ARCHIVO ESPAÑOL DE ARTE, LXXXI, 322

ABRIL-JUNIO 2008, pp. 115-138

ISSN: 0004-0428

\title{
PAISAJES DECIMONÓNICOS ESPAÑOLES
}

\author{
POR \\ ENRIQUE ARIAS ANGLÉS \\ CSIC
}

En este estudio se dan a conocer, catalogan y analizan una serie de pinturas de paisaje del siglo XIX español de diferentes autores, que han ido apareciendo en los últimos años en colecciones particulares y en el comercio nacional e internacional. Son obras de Jenaro Pérez Villaamil, Antonio de Brugada, Carlos de Haes, Antonio Muñoz Degraín y Marceliano Santa María; ya estos dos últimos artistas a caballo entre el siglo XIX y el XX, pero plenamente decimonónicos por sus concepciones pictóricas.

Palabras claves: Pintura de paisaje; Siglo XIX español; Jenaro Pérez Villamil; Antonio de Brugada; Carlos de Haes; Antonio Muñoz Degraín; Marceliano Santa María.

A series of nineteenth-century Spanish landscape paintings by different artists that have come to light in recent years in private colections and on the national and international art markets are here brought together and studied. These works are by Jenaro Pérez Villaamil, Antonio de Brugada, Carlos de Haes, Antonio Muñoz Degraín and Marceliano Santa María -the last two artists bridging the $19^{\text {th }}$ and $20^{\text {th }}$ centuries, but whose pictorial conceptions remained in the nineteenth.

Key words: Landscape painting; $19^{\text {th }}$ century; Spain; Jenaro Pérez Villaamil; Antonio de Brugada; Carlos de Haes; Antonio Muñoz Degraín; Marceliano Santa María.

En el presente trabajo se dan a conocer y catalogan una serie de pinturas de paisaje del siglo XIX español de diversos autores, que han ido apareciendo en los últimos años en colecciones particulares y en el comercio nacional e internacional, y que, ante la exigüidad que representarían sus estudios individualizados, he esperado reunir el número suficiente de ellas como para poder dar cuerpo a un pequeño estudio. Se trata de obras de Jenaro Pérez Villaamil, Antonio de Brugada, Carlos de Haes, Antonio Muñoz Degraín y Marceliano Santa María; ya estos dos últimos artistas a caballo entre el siglo XIX y el XX, pero plenamente decimonónicos por sus concepciones pictóricas.

Comenzaremos con las obras del paisajista romántico Jenaro Pérez Villaamil (Ferrol, 1807-Madrid, 1854), del que traemos varios cuadros. Siguiendo un orden cronológico, el primero de ellos es el titulado A procession around the Cathedral of Seville (Fig. 1), en el catálogo de la subasta de Christie's celebrada en el Rockefeller Plaza de New York en el 
Fig. 1. Jenaro Pérez Villaamil. A procession around the Cathedral of Seville. O/L. Nueva York. En el comercio.

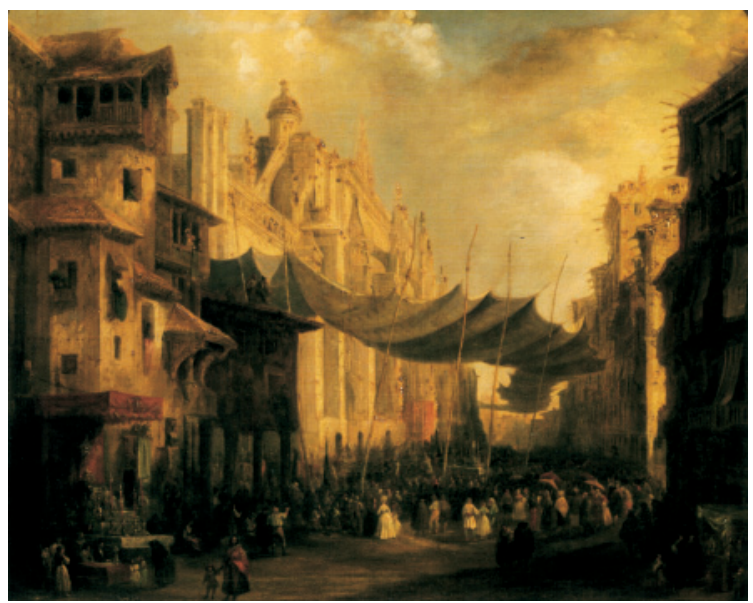

$2007^{1}$, donde ha aparecido. Se trata de un óleo sobre lienzo de 79,4 ×97,2 cm., sin firma ni fecha, pero que, por su estilo y técnica, es claramente una obra de Pérez Villaamil, y de las de muy buena calidad. Representa, como expresa su descriptivo título, una procesión entrando en la catedral de Sevilla, al parecer por la puerta lateral del Evangelio o sea, la que da a la calle del palacio arzobispal. Como en tantas obras de Pérez Villaamil, se nos muestra al monumento en su entorno urbano, tanto arquitectónico como social; en este caso mediante el protagonismo de una procesión, que da pretexto no sólo para expresar un tipo de ceremonial que caracteriza a la ciudad del Betis, y que marca un aspecto fundamental de su personalidad, sino también para subrayarlo, llenando el ámbito callejero con multitud de personajillos de toda índole social -patente por sus atuendos-, que se aglomeran en torno a su icono religioso, prestándole así ese sentido de unidad a que aludimos. La técnica empastada y suelta, característica de las obras de Pérez Villaamil, con especial resalte en los adornos arquitectónicos en los que incide la luz, así como también en las vestimentas de los personajes. Y, sobre todo, ese tono dorado y atmósfera vaporosa que prestan a las arquitectura tenues luces de dorado atardecer, que parece reflejarse también en los celajes.

Aunque carece de fecha, por su estilo, aún muy próximo al de las obras de en torno a 1830 de David Roberts, así como por sus grandes semejanzas temáticas y estilísticas con dos obras de la antigua colección Adanero tituladas Vista de la Giralda de Sevilla desde la calle de la Borceguinería e Interior de la catedral de Sevilla ${ }^{2}$ (ambas en colecciones particulares. Madrid), que forman pareja, estando fechada la primera en 1833 y posiblemente la otra también, podemos intentar datarla precisamente por esa fecha; lo que estaría además apoyado por el hecho de que el Interior de la catedral de Sevilla, de la antigua colección Adanero, representa la entrada de una procesión en la catedral, plagada de personajes de todas clases sociales, como si su asunto fuese una continuación secuencial (del exterior al interior del templo) del cuadro que estudiamos. Por ello, creemos que el cuadro forma parte de la serie de obras sobre Sevilla que realizó el mismo año en que conoció a David Roberts en dicha capital andaluza.

De fecha algo posterior al cuadro anterior es el titulado Interior de la iglesia de San Juan de los Reyes de Toledo (Fig. 2), aparecido en el mercado de Londres y, posteriormente, traído al de

1 19th Century European Art \& Orientalist Art. Christie's. Rockefeller Plaza, New York, April 12, 2007, lot number 0241, sale number 1819 .

2 Arias Anglés, E. El paisajista romántico Jenaro Pérez Villaamil, CSIC, Madrid, 1986, p. 207, núm. 12 (lám. II y Fig. 11) y p. 279, núm. 251 (lám. III y Fig. 103). 
Madrid. Es un óleo sobre lienzo, de $89 \times 114,2 \mathrm{~cm}$., firmado y fechado en la parte baja central, en la sepultura: "Genaro Perez / Villamil 1839". En el reverso, pegadas al bastidor, hay tres notas de papel escritas en inglés y en caracteres de máquina de escribir muy antigua. Una es una pequeña biografía de Pérez Villaamil, con nombre y fechas equivocados; otra indica que el cuadro pertenecía a la colección del obispo de Exeter; y la tercera lleva escrita la fecha de 1839.

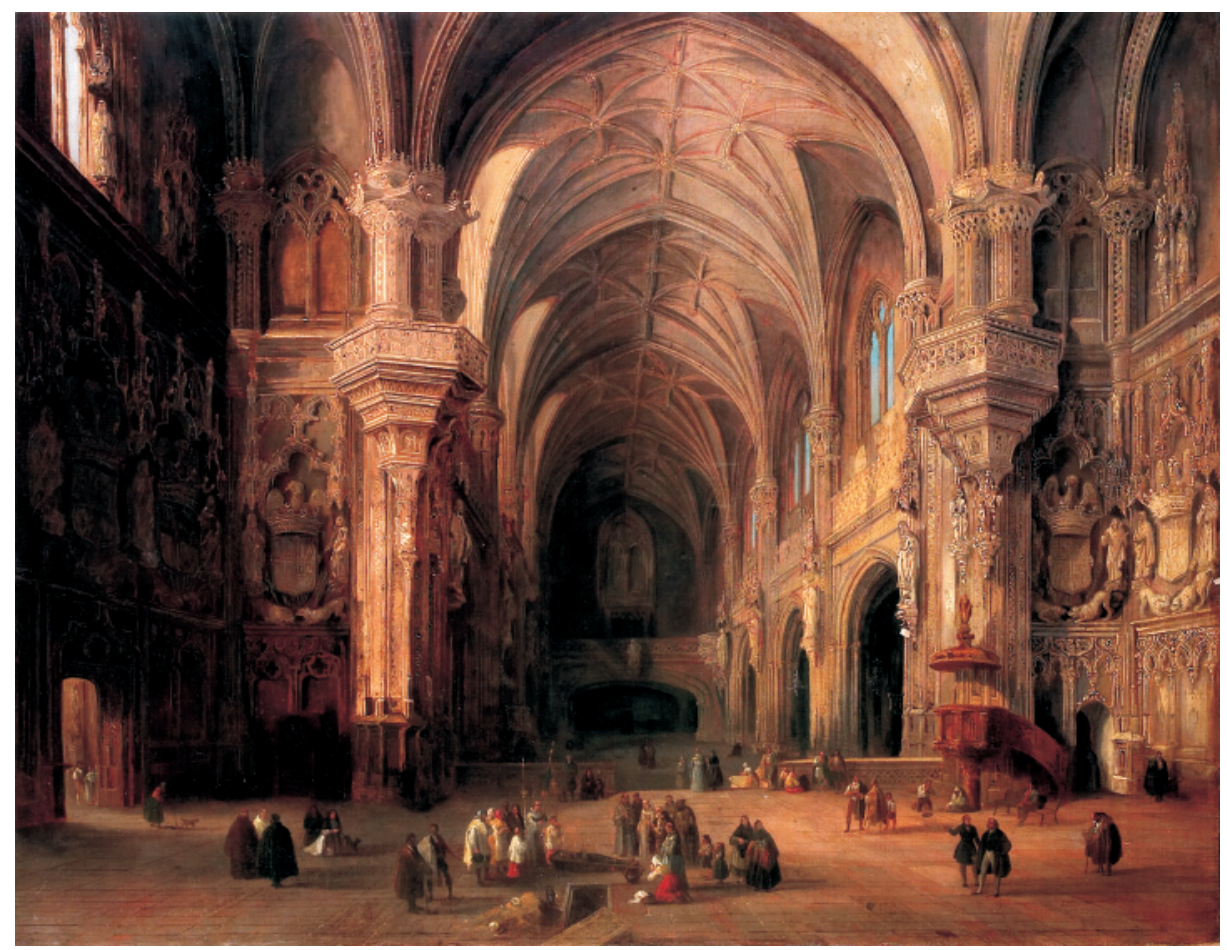

Fig. 2. Jenaro Pérez Villaamil. Interior de la iglesia de San Juan de los Reyes de Toledo. O/L. Londres-Madrid. En el comercio.

Desde el punto de vista temático, se trata de un hermoso interior de templo gótico muy representativo del artista; asunto este que fue uno de los más significativos y personales dentro de la producción de Pérez Villaamil. Estos interiores de iglesias están concebidos, generalmente, a modo de una visión paisajística, dejando que nuestra vista se extienda por los dilatados espacios en huidizas perspectivas entre afiligranados pilares (que sustituyen aquí a los elementos geológicos), y luminosas vidrieras, que parecen tamizar la luz solar con efectos similares a los del ocaso entre las nubes. Unas veces, estas vistas de interiores de monumentos arquitectónicos son creaciones de fantasía, otras están tomadas de la realidad con gran fidelidad hasta en los detalles, reduciéndose el elemento fantástico al alargamiento de las proporciones del edificio, la amplificación del ámbito, así como a la poética atmósfera que lo envuelve. Éste es el caso del cuadro que tratamos, el cual nos muestra el acrecentado interior de la iglesia de San Juan de los Reyes de Toledo, vista desde el altar mayor hacia los pies del templo, donde se halla el coro, pudiéndose también ver parte del reducido crucero adornado con los grandes escudos sostenidos por águilas, elementos ambos muy característicos de este tipo de iglesias de los Reyes Católicos. Como es habitual en los interiores de iglesias de Pérez Villaamil, su ámbito se adorna con personajillos populares o de épocas históricas -inconfundibles desde el punto de vista técnico, realizados 
normalmente con esa factura tan acabada, con abundante empaste pictórico y algunos toques de color cálido-, asistiendo, generalmente, a una ceremonia religiosa. Tienen por función, sin duda, la de proporcionar sabor popular o histórico al monumento, componiendo alguna anécdota que, en el caso que tratamos, se trata del entierro del algún personaje religioso en un sepulcro del suelo del templo.

En cuanto a la factura general del lienzo, es también la inconfundible que emplea, generalmente, Pérez Villaamil: riqueza de empaste y colorido cálido, conformando una luminosidad que se pierde en penumbras desvaídas y algo misteriosas hacia los fondos del cuadro; así como son también muy características las filigranas, como de labor de encaje, que efectúa con la pasta pictórica para resaltar los toques luminosos en los adornos escultóricos que acompañan a los elementos arquitectónicos, patentes sobre todo en los arquillos góticos, en los escudos, en las esculturas, y en los afiligranados capiteles de los pilares de las naves.

Y, por último, desde el punto de vista histórico, sabemos que Pérez Villaamil anduvo dibujando monumentos toledanos en 1839 y $1840^{3}$, año este último en el que sale de España para su exilio a Francia y Bélgica entre 1840 y 1844, etapa de la Regencia del General Espartero. Pero, además, conocemos hoy día que Pérez Villaamil pasó de Francia a Gran Bretaña en una corta estancia en 1841, escribiéndole una carta desde Londres, en agosto de ese año, a su amigo David Roberts, que sin duda estaba fuera de dicha capital. En ella le dice que ha traído a Londres siete cuadros suyos que se hallan colgados en la casa Collnaghi, que los quiere vender (pues le cuestan más en transportes y derechos de aduanas que lo que valen) y le ruega que los recomiende entre sus amigos para que se los compren ${ }^{4}$. Pues, bien, pudiera ser (y es más que probable) que uno de estos siete cuadros fuese el que estudiamos, dada su procedencia de las colecciones británicas de Lady Manners y del obispo de Exeter ${ }^{5}$. Nosotros nos inclinamos por esta última posibilidad, pues la fecha de 1839 que lleva el lienzo no indicaría más que Villaamil llevó consigo cuadros suyos en su viaje al extranjero, como cartas de presentación de su calidad artística y también con el objeto de poder ayudarse a sobrevivir con su venta hasta alcanzar un afianzamiento profesional.

Posteriormente, entre el 11 de febrero y el 17 de marzo de 1843, nuestro artista pintaría en Lovaina, su lugar de residencia en Bélgica, otro Interior de San Juan de los Reyes, en Toledo, cuadro al que cita repetidas veces en su Diario, entre esas fechas, por las dificultades que le supuso su realización: "11 de febrero. Preparo mi interior grande de San Juan de los Reyes, muy bien de línea". Una vez concluido el cuadro lo envió a la Exposición de La Haya de ese año, siendo adquirido por el "Rey viejo" (Guillermo I de Holanda, que había abdicado en 1840 en Guillermo II) en 600 florines $^{6}$. Esto no debería de extrañarnos, pues o bien se trataba de otro diferente interior de dicho templo o, lo que también fuese más probable, una réplica de este que estudiamos, dado que Villaamil, como hemos dicho, hizo reproducciones, con ligeras variantes, de cuadros que, por su temática, tuvieron fácil venta. Y más, cuando, refiriéndose al Interior de San Juan de los Reyes, en Toledo que pintó en 1843, y que le adquirió el "Rey viejo" de Holanda, dice literalmente "Preparo mi interior grande de San Juan de los Reyes". Esta precisión de "grande" implica, sin duda, la existencia anterior de otra versión más pequeña de ese cuadro, versión que pudiera ser que fuese esta que ahora ha aparecido, procedente de una antigua colección inglesa, en el comercio de Gran Bretaña.

\footnotetext{
3 Ibidem, pp. 75 y 78.

${ }^{4}$ Arias Anglés, E., "Pérez Villaamil en Inglaterra”, en Archivo Español de Arte, t. LXXV, n. ${ }^{\circ}$ 299, julio-septiembre 2002, pp. 322 a 326.

5 19th Century European Art, Christie's, London, 16 november 2006, p. 88, n. ${ }^{\circ} 64$.

${ }^{6}$ Arias Anglés, E., El paisajista romántico Jenaro Pérez Villaamil, CSIC, Madrid, 1986, pp. 235 (núm. 101), y 236.
} 
En el año 2000, llegó a mis manos, por medio del Étude Tajan de París, otra hermosa obra de Pérez Villaamil, a la que le habían dado el descriptivo título de Vue fantaisiste d'une ville espagnole avec un caprice de la Casa del Rey Don Pedro de Alcalá de Henares (Fig. 3), y que nosotros mantenemos por responder con bastante exactitud a lo que el pintor quiso representar. Es un óleo sobre tela de $108 \times 145 \mathrm{~cm}$., firmado y fechado en la parte baja izquierda sobre una piedra: "Genaro Perez / de Villamil / Paris / 1841". Se trata, en efecto, de una composición de fantasía, en la que el pintor se inventa un pueblo español imaginario, construido con algunos elementos de ficción y otros tomados, más o menos, de la realidad, como la caprichosa interpretación de la Casa del Rey Don Pedro de Alcalá de Henares, el castillo del fondo con recuerdos del de Alcalá de Guadaira de Sevilla y, junto a él, el enorme puente cruzando un gran barranco en la serranía que tiene remembranzas del Tajo de Ronda. Es obra de mucho empaste, factura suelta y colorido de tonos dorados, muy característica, temática y técnicamente del pintor, como ya hemos visto. Y, como precisa la mención que se hace en la firma, fue pintado en París en 1841, o sea, en el primer año de su exilio en Francia y Bélgica entre 1840 y 1844. Villaamil tuvo durante todo este tiempo casa en París, aunque anduviese viajando, manteniéndola incluso durante su estancia en Bélgica, desde los últimos meses de 1842 hasta mayo de $1843^{7}$, en que regresa a París. Es, pues, en ese primer año de estancia en Francia, cuando pinta este cuadro, que debió de vender allí en ese mismo año, porque no consta en la lista de obras que da en su "Diario" como dejadas por él en París a su regreso a España en $1844^{8}$.

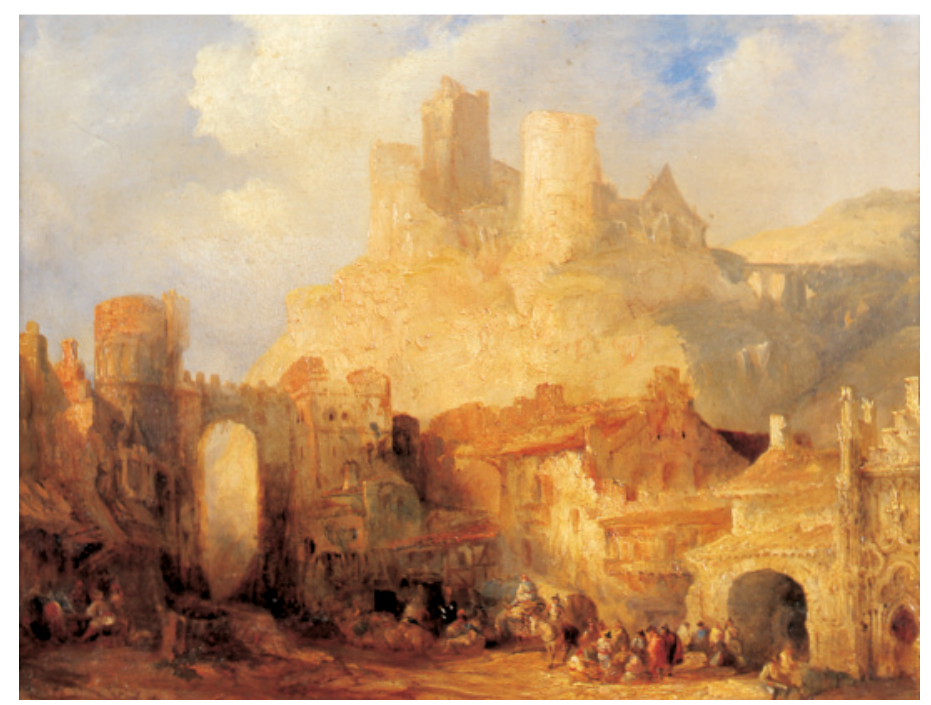

Fig. 3. Jenaro Pérez Villaamil. Vue fantaisiste d'une ville espagnole avec un caprice de la Casa del Rey Don Pedro de Alcalá de Henares. O/L. París. En el comercio.

Supuestamente, pintado también en París, es el cuadro que representa la vista de un interior de catedral gótica, que hemos titulado Interior de la catedral de Lieja (Fig. 4), por creer que se trata de dicho templo, como a continuación expondremos. Es obra aparecida en el comercio madrileño y que fue adquirida por el Museo de La Coruña, donde actualmente se conserva. Se trata de un óleo sobre lienzo de 96,5 × 129,5 cm., que está firmado y fechado en el ángulo inferior izquierdo: "Genaro Perez / de Villaamil / Paris. 1846". Como decimos, creemos que nos muestra el interior de la catedral de Lieja, debido a que se conserva, también en el Museo de La Coruña,

\footnotetext{
7 Ibidem, p. 549, nota de su Diario referente al 7 de mayo.

${ }^{8}$ Ibidem, p. 554, nota referente al día 13 de enero de 1844.
} 
Fig. 4. Jenaro Pérez Villaamil. Interior de la catedral de Lieja (Bélgica). O/L. Museo de La Coruña.

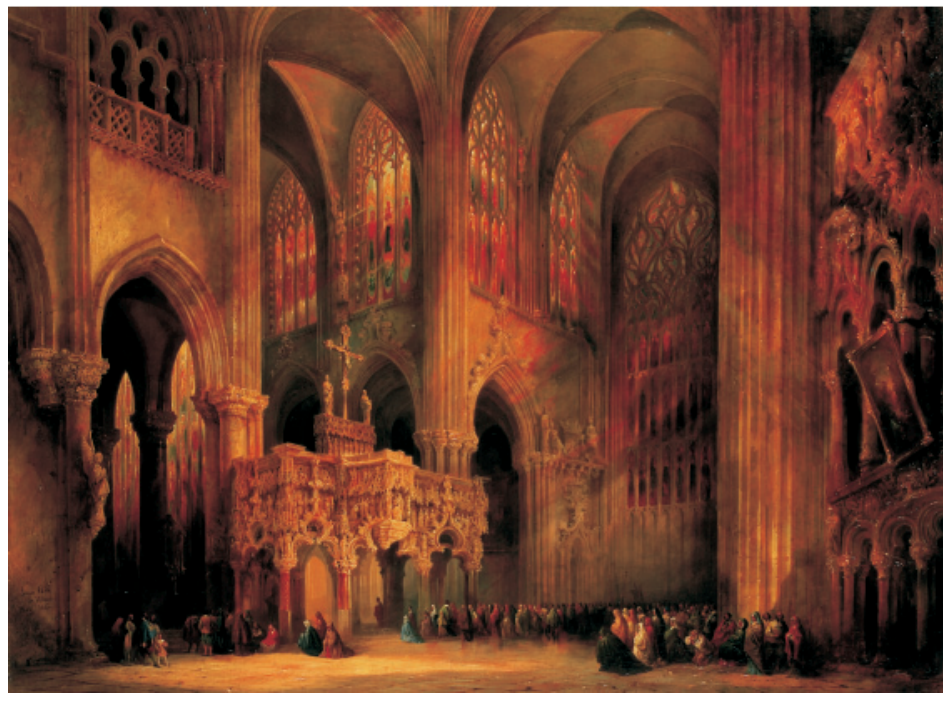

un dibujo acuarelado de Pérez Villaamil representando el templete gótico flamígero que centra la composición de este cuadro y que es, sin duda, un bosquejo preparatorio del mismo ${ }^{9}$. Se trata de un elemento típico de las iglesias belgas denominado "Jubé" que, a modo de arco de triunfo, da acceso a la capilla principal y coro de la iglesia y que, según opinión de Gaya Nuño ${ }^{10}$, se trata, en el caso de este dibujo, del "Jubé" de Saint Jacques de Lieja; aunque, anteriormente, MartínezBarbeito ${ }^{11}$ lo hubiera clasificado como el interior de la catedral de Bruselas.

Como antes dijimos, sabemos que Pérez Villaamil vivió y pintó en Bélgica entre septiembre de 1842 y mayo de 1843, según nos consta por el "Diario"12 que escribió durante su salida al extranjero entre 1840 y 1844; especificándonos el artista en dicho "Diario", que entre los días 18, 19 y 20 de marzo de 1843 empezó a pintar, en su estudio de Lovaina, el Interior de Saint Jacques de Lieja ${ }^{13}$, óleo que realizó, sin duda, sobre apuntes (dibujos y acuarelas, como hemos visto) tomados previamente del natural, siguiendo la costumbre de todos los pintores románticos de realizar los cuadros en el taller. De hecho, sabemos que una acuarela con el título de Interior de la iglesia de Santiago de Lieja se exhibió en 1913 en la "Exposición de pinturas españolas de la primera mitad del siglo XIX", organizada por la Sociedad Española de Amigos del Arte en el Banco Hipotecario de Madrid, y que pertenecía entonces a la colección de D. Eugenio García Perate $^{14}$. Pensamos que probablemente se trate de un estudio preparatorio de esta obra que analizamos, pues aunque en el catálogo de la citada exposición se le cita solamente con el título de Interior de la iglesia de Santiago, posteriormente, en 1921, Vegue y Goldoni y Sánchez Cantón que, sin duda, conocieron la obra, refiriéndose a esa exposición, mencionan esta acuarela con el

\footnotetext{
9 Ibidem, p. 300, núm. 325 (Fig. 122).

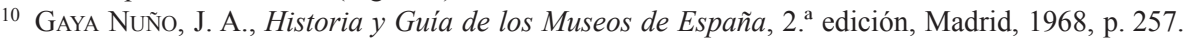

11 Martínez-Barbeito, I., Museo Provincial de Bellas Artes de La Coruña. Catálogo. La Coruña, 1957, p. 62, núm. 116, lám. 8 .

12 Méndez Casal, A., Jenaro Pérez Villaamil. Madrid (s.a.) [1921], p. 43 y siguientes; ArIAs Anglés, E., El paisajista romántico Jenaro Pérez Villaamil. CSIC. Madrid, 1986, documento núm. 287, p. 537 y siguientes.

13 Méndez CAsal, Op.cit. nota 12, p. 52; Arias Anglés, Op. Cit. nota 12, p. 547.

${ }^{14}$ Exposición de Pinturas Españolas de la Primera Mitad del Siglo XIX. Catálogo Ilustrado. Sociedad Española de Amigos del Arte. Banco Hipotecario. Madrid, mayo-junio, 1913, p. 19, núm. 6; ArIAS AnglÉs, E., El paisajista romántico Jenaro Pérez Villaamil, Madrid, CSIC, 1986, p. 305, num. 342.
} 
título de Interior de la iglesia de Santiago de Lieja ${ }^{15}$. Aunque desconozcamos dicha acuarela, tiene todos los visos de ser un estudio preparatorio de este cuadro. Entonces ¿por qué está fechado el cuadro que estudiamos en 1846 y no en 1842-1843? Desde luego, no se trata de ningún contrasentido pues, posteriormente a esta salida al extranjero por Francia, Inglaterra, Bélgica y Holanda entre 1840 y 1844, Pérez Villaamil vuelve a marchar a Francia entre mayo y agosto de $1844^{16} \mathrm{y}$, por tercera vez, regresa a París en $1846^{17}$, sin duda llevando cuadros para vender entre la clientela que allí él ya conocía: miembros de la aristocracia, ricos burgueses e, incluso, el propio rey Luis-Felipe, que ya le había comprado cuadros anteriormente. Cosa nada de extrañar, pues igualmente procedió en el corto viaje que hizo a Londres en 1841, dejando cuadros suyos que allí llevó para que se encargara de venderlos su amigo el pintor escocés David Roberts, como ya vimos. Pues bien, pensamos que este cuadro es uno de esos que llevaría a París para su venta en 1846, lo que apoya también que haya aparecido en una subasta de Amsterdam, pues, probablemente, su comprador fuese entonces algún personaje belga, dado el asunto del cuadro. Y, con respecto a estar fechado en París en 1846, no obsta para que, con seguridad, lo realizara en 1843 en Lovaina, lo trajese a España, sin firmar ni fechar, a su regreso en 1844, y lo llevara de nuevo a París en 1846, donde lo firmó y dató en ese año para su exposición y venta, posiblemente por no encontrar en España clientela para un asunto de Bélgica; pues el corto tiempo que permaneció ese año de 1846 en París hace prácticamente imposible que pintara allí ningún óleo. Desde el punto de vista técnico, la factura responde plenamente a la empleada por Pérez Villaamil en este tipo de composiciones, y a la que ya hemos repetidamente aludido: riqueza de empaste y un colorido cálido, con una luminosidad de tonos dorados que confiere al interior del monumento matices de atardecer, conformando así una atmósfera como de ensueño. Igualmente, son aquí muy características del artista gallego las ya comentadas filigranas, como de labor de encaje, que efectúa con la pasta pictórica para resaltar los golpes de luz en los adornos escultóricos que acompañan a los elementos arquitectónicos.

Los dos cuadros que de Pérez Villaamil traemos a continuación fueron subastados por Sotheby's en Londres en noviembre del $2006^{18}$ y, aunque posean las mismas dimensiones y estilísticamente los haga estar muy próximos, no creemos, sin embargo, que formasen pareja en origen. El primero que vamos a tratar, por considerarlo de mayor importancia, es el titulado Ribera del Sil (Valle de Quiroga) (Fig. 5), que es un óleo sobre lienzo, de 66,5 × 81,5 cm., firmado, fechado y dedicado en el ángulo inferior izquierdo: "Genaro P. Villamil / A sus hermanos / Dic. 18(4)6", llevando, además, en el ángulo inferior derecho, una inscripción autógrafa del pintor indicando el lugar representado: "Rivera del Sil / en Boyros / Valle de Quiroga". El cuadro tiene el valor añadido de las inscripciones autógrafas del pintor en ambos ángulos inferiores; no sólo firmándolo, sino también fechándolo, dedicándoselo a sus hermanos y especificándonos el lugar que ha representado. Todo esto resulta muy interesante; en primer lugar, porque Pérez Villaamil, aunque firmó muchas obras y dató menos, solamente realizó otro tipo de inscripciones en determinados cuadros a los que él concedería algún valor especial, bien por pintarlos para alta clientela, bien por algún motivo amistoso, sentimental, o incluso, en algún caso, bromeando con el mucho trabajo que le había llevado su realización. En segundo lugar, porque la fecha de

\footnotetext{
15 Vegue y Goldoni, A. y Sánchez Cantón, F. J., Tres salas del Museo Romántico, catálogo, Madrid, 1921, p. 121; Arias ANGLÉs, E. op. cit. nota 14.

${ }^{16}$ Méndez Casal, A., Jenaro Pérez Villaamil, Madrid, s.a. [1921], p. 59; Arias Anglés, E. op. cit., nota 14, pp. 121, 122 y 557.

17 ARIAS Anglés, E., El paisajista romántico Jenaro Pérez Villaamil, CSIC, Madrid, 1986 pp. 121 a 123 y 465 (documento núm. 72).

18 Spanish Painting 1850-1930 (1850-1930 Pintura Española). Sotheby's, London, 15 november 2006, pp. 84-85, lots $210-211$.
} 


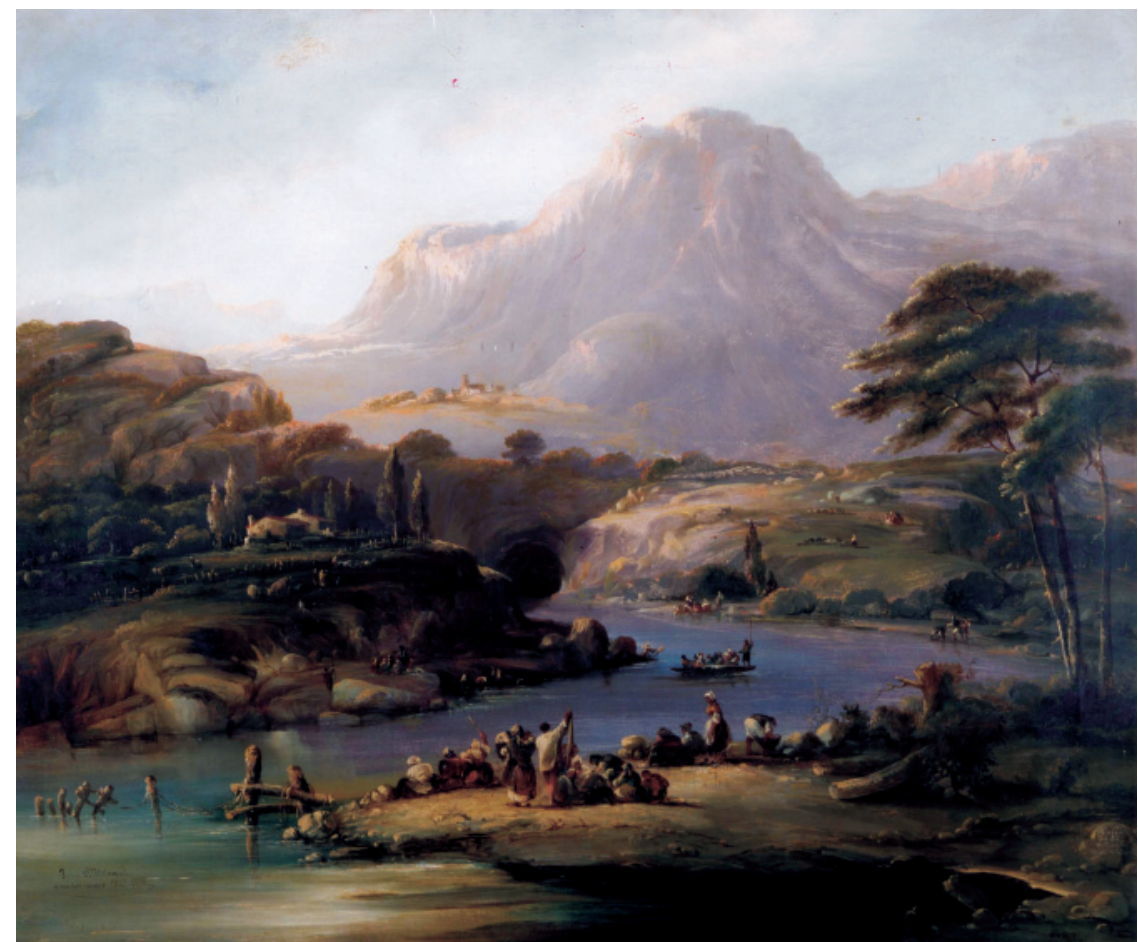

Fig. 5. Jenaro Pérez Villaamil. Ribera del Sil (Valle de Quiroga). O/L. Londres. En el comercio.

1846, nos indica que pintó el esbozo del lienzo durante el viaje que realizó a Asturias y Galicia en septiembre de ese año ${ }^{19}$, ejecutando el cuadro definitivo posteriormente, en diciembre, en su estudio. En tercer lugar, porque la dedicatoria que hace del cuadro a sus hermanos, junto con la especificación del lugar del paisaje representado, le dan un valor documental al lienzo y nos indica que muchos paisajes de Pérez Villamil fueron tomados del natural, y que no todos representan fantasías; $y$, además, porque esas inscripciones nos ponen también a este cuadro en relación con otro que publicamos y catalogamos hace unos años, que carece de fecha, pero que, por las inscripciones autógrafas del artista que también lleva, se relaciona claramente con este que tratamos, viniendo a ser así uno continuación del otro, en una especie de secuencia paisajista. Todo ello, unido a su idéntico tamaño, hace que podamos considerarlos (en este caso sí) como pareja.

En efecto, existe otro cuadro, perteneciente a la colección Narváez Lezámiz de Bilbao, que publicamos en su día con el título de Torrente del Navia (Valle de Quiroga) ${ }^{20}$, óleo sobre lienzo de $67 \times 81,5 \mathrm{~cm}$., que lleva una inscripción abajo y al centro que reza: "A sus hermanos / Genaro Perez / de Villamil", y en el ángulo inferior izquierdo otra indicativa del lugar representado: "Torrente del Navia / Bajada del Sil / en el valle de Quiroga". Aunque este cuadro carezca de fecha, es evidente que se encuentra en clara relación con el que estamos tratando, teniendo que estar realizado su esbozo igualmente durante ese viaje del pintor a Galicia y Asturias en 1846 y siendo ejecutado definitivamente también por las mismas fechas. Indudablemente, según lo

\footnotetext{
19 ArIas Anglés, E., op. cit., nota 17, pp. 125 a 127.

20 Arias Anglés, E., op. cit. nota 17, p. 277 (núm. 243); Enrique Arias Anglés (comisario), Tres grandes maestros del paisaje decimonónico español: Jenaro Pérez Villaamil, Carlos de Haes y Aureliano de Beruete. Centro Cultural del Conde Duque, Madrid, 1990, p. 244, núm. 33.
} 
expuesto, los dos cuadros forman pareja: uno y otro están dedicados a sus hermanos, pintados para ellos, poseyendo las mismas dimensiones y representando dos parajes consecutivos de un mismo escenario geográfico. A todo ello debemos añadir que ambos cuadros están realizados con la misma técnica, típica de Pérez Villaamil, con empastes en las rocas iluminadas, en los personajillos, inconfundibles del pintor, en los maderos del embarcadero y puente, tan semejantes en uno y otro cuadro, así como las mismas poéticas lejanías montañosas con celajes de atardecer, tan características del artista.

El otro cuadro subastado en Sotheby's lleva por título Naufragio en la playa (Fig. 6) ${ }^{21}$, y es un óleo sobre lienzo, de $66,5 \times 81,5 \mathrm{~cm}$. Por el tipo de temática y estilo podríamos situar la época de su realización en torno a 1840 . Ya que estos asuntos de tempestades y naufragios de navíos junto a la costa fueron tratados, a menudo, por el pintor durante la que he denominado su "etapa prerromántica", que discurre entre su llegada a Cádiz en 1823 (cuando se hace pintor) y su regreso de Puerto Rico en 1833 (cuando conoce a David Roberts y asimila su estilo británico). En esta década, el principal influjo, entre otros, que recibe la pintura de Pérez Villaamil es el de los pintores prerrománticos franceses del siglo XVIII J. Pillement y C. J. Vernet; especialmente, son de destacar sus interpretaciones personales de las vistas costeras con tempestades y naufragios junto a la costa de C. J. Vernet. Este tipo de asunto raramente volvió a tratarlo Pérez Villaamil posteriormente a aquellas fechas; y es por lo que pensamos que la realización de este cuadro, tan próximo temáticamente (aunque no técnicamente) a las producciones de ese tipo de C. J. Vernet, no debe de hallarse muy lejana de esa primera etapa prerromántica en que asiduamente los trató. Quizá, el asunto tan romántico de las fuerzas desatadas de la Naturaleza y el hombre empequeñecido e indefenso ante ellas (ejemplificado en el mar, al gusto de C. J. Vernet), debió de tentarle una vez más, teniendo aún el recuerdo próximo, aunque raramente ya lo volviera a representar en adelante. No hay duda de que la remembranza de obras de este tipo de C. J. Vernet está presente en la composición, reuniendo los ingredientes básicos que el francés utilizó en estos asuntos: los grandes acantilados, el mar embravecido chocando furiosamente contra las rocas y la playa, el barco luchando con las olas, el naufragio y los hombres empequeñecidos enfrentándose al oleaje. Pero se queda sólo en eso, ya que se trata aquí de la superación del recuerdo de un modelo pictórico de juventud, elevándose por encima de él en una interpretación personal del tema, tanto en la forma de tratarlo como en la técnica de realización. Pérez Villaamil marca claramente en este cuadro las diferencias que median entre las obras suyas de este tipo que realizó en su etapa prerromántica, bajo la influencia de la pintura dieciochesca francesa, y lo que es una obra suya de madurez, íntegramente romántica, aun tratándose de un asunto similar. Por lo demás, la técnica es plenamente característica de la etapa romántica de Pérez Villaamil, empastada y suelta, con resaltes en la espuma del oleaje y en los personajillos, muy peculiares del pintor en su forma de ejecutarlos, estando algunos de la parte izquierda del grupo simplemente esbozados mediante somero dibujo con el color, sin llegar a empastarlos, como medio acabados; detalle éste, inconfundible, que hemos visto en otros cuadros suyos. Igualmente sucede con la factura de los celajes, con ese colorido sonrosado, crepuscular, tan peculiar de muchas de sus representaciones. El cuadro estaba en torno a 1975 en la colección del Dr. R. Bartoloti, en Madrid, donde pude verlo en su día, siendo posteriormente publicado por mí en mi libro sobre el artista, aunque sin fotografía, por carecer de una buena, pero dando una clara descripción del asunto ${ }^{22}$ que, como se puede comprobar, coincide plenamente con el de este cuadro.

\footnotetext{
21 Op. cit. nota 18.

22 Enrique Arias Anglés, El paisajista romántico Jenaro Pérez Villaamil, CSIC, Madrid, 1986, p. 269, núm. 208.
} 
Fig. 6. Jenaro Pérez Villaamil. Naufragio en la playa. $\mathrm{O} / \mathrm{L}$. Londres. En el comercio.

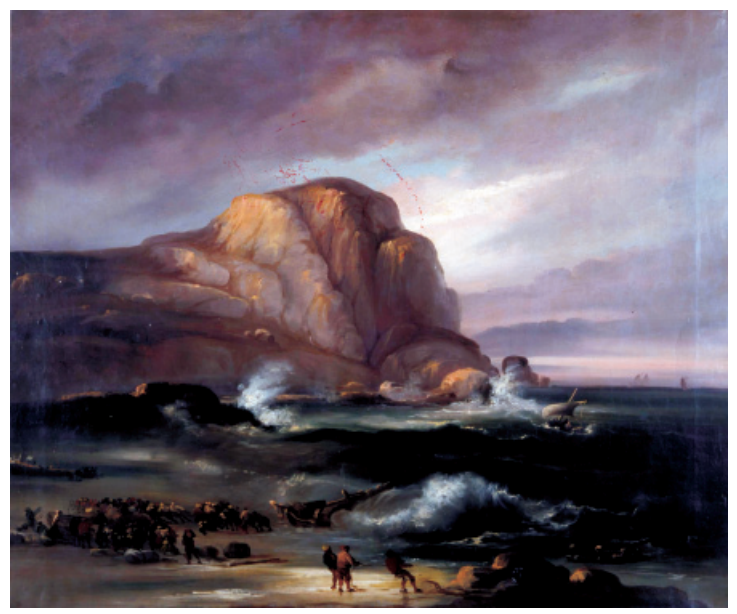

Los siguientes cuadros de Villaamil que traemos, son dos hermosos óleos sobre lienzos que llegaron a mí, hace unos años, por medio de fotografías, teniendo los dos, al parecer, las mismas dimensiones $(60 \times 79 \mathrm{~cm}$. $)$ que aparecen escritas en la foto del que primeramente vamos ahora a tratar, y que está firmado y fechado hacia el ángulo inferior izquierdo "Villa-amil/1844". Representa una Vista de población fantástica (Fig. 7), compuesta a base de edificios de tipo belga y español y situada en medio de un paisaje montañoso, teniendo al primer término, a los pies del caserío, un río con cascada y barcas con personajes populares. En medio de la población, entre casas de tipo belga, surge una descomunal y fantástica iglesia de un gótico de difícil localización; cercana a ella, en la parte derecha del cuadro, vemos un castillo de fácil filiación española. La técnica y el estilo son claramente villaamilescos y la fecha de 1844 nos indica que lo realizó, o bien en el último mes de su estancia en Francia (en enero de ese año), o a lo largo del mismo año, a partir de febrero, en que regresa a España ${ }^{23}$. El otro lienzo, que titularemos Paisaje costero (Fig. 8) parece no tener ni firma ni fecha, y representa un paisaje costero, con barcas y personajes populares en la playa que discurre al primer término, viéndose, más allá, a la derecha, un pueblecito pesquero y, más al fondo, unos grandes acantilados. Se trata, sin duda, de una costa extranjera por el tipo de vestimenta de los personajes populares que adornan su ámbito. Tanto en uno como en otro cuadro, la técnica empastada, resaltada incluso en algunas zonas, las luces de atardecer con celajes dorados, la fantasía ambiental (sobre todo en el primero), el estilo, en suma, es característico de Pérez Villaamil.

De las tres últimas obras de Pérez Villaamil que vamos a citar, destacaremos primeramente, por su cierto empaque de cuadro de mediano tamaño, el que titularíamos Ceremonia religiosa en el interior de la sinagoga del Tránsito de Toledo (Fig. 9), obra aparecida en el 2004 en la sala de subastas que Caja El Monte tenía en Madrid, y que fue retirada por sus dueños antes de la subasta, abonando el préstamo que la gravaba. Por ello, sólo puedo ofrecer testimonio de ella por medio de fotografía, desconociendo las medidas, aunque recuerdo que era óleo sobre lienzo, de mediano tamaño y que estaba firmada. Representa un detallado interior de la sinagoga del Tránsito (plagada de personajes vestidos de burgueses), respondiendo a una exacta representación de la realidad del monumento, aunque tamizado todo el ámbito por una luminosidad de tonos ocres que le proporciona una atmósfera casi misteriosa. El segundo de estos tres es un cuadrito muy curioso, que titularemos Interior de iglesia con sepulcros yacentes (Fig. 10), y que es óleo

\footnotetext{
23 Ibidem, p. 554.
} 


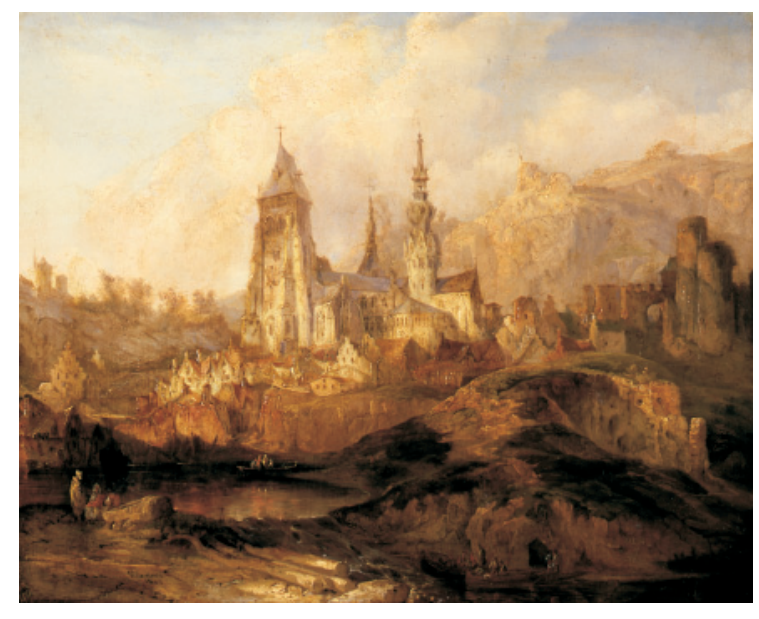

Fig. 7. Jenaro Pérez Villaamil. Vista de población fantástica. O/L. Paradero desconocido.

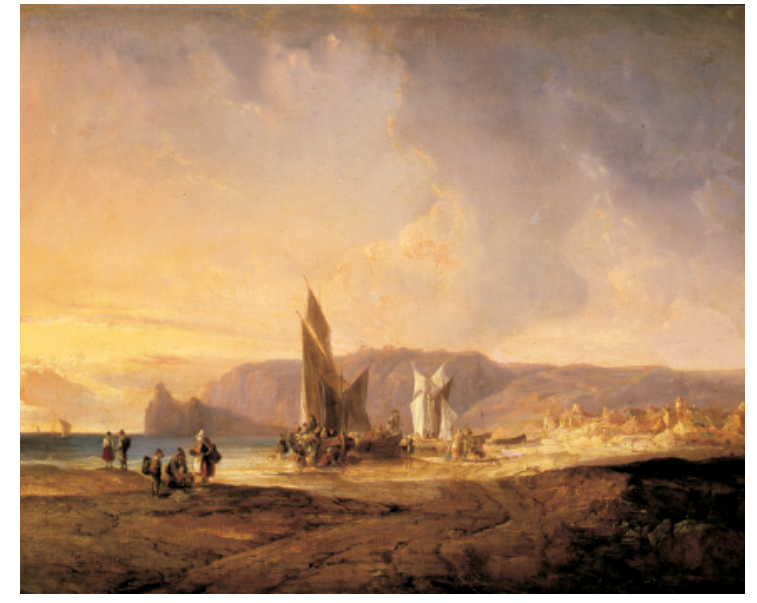

Fig. 8. Jenaro Pérez Villaamil. Paisaje costero. O/L. Paradero desconocido.

sobre lienzo, de $21 \times 28 \mathrm{~cm}$, dedicado y firmado en el ángulo inferior de la obra: "a Villoslada. Villaamil. 1849". Y decimos que es curioso este bello cuadrito, no sólo por su singular y esbozado interior de iglesia gótica con personajes populares y ceremonia religiosa, tan característico de Pérez Villaamil, sino, además, por la dedicatoria, ya que se lo brinda al literato romántico Navarro-Villoslada, siendo, por tanto, testimonio directo del conocimiento y amistad entre ambos, pintor y escritor; trato que debió gestarse por frecuentar los dos los mismos ambientes culturales de la época, como el Liceo Artístico y Literario Español, al cual pertenecían ambos, y donde era habitual la colaboración entre escritores y artistas. Y, por sus características, este cuadro parece ser una de las obras de competición que realizaban los pintores en las sesiones nocturnas del Liceo ante el público, al igual que improvisaban también las suyas los literatos y poetas. El cuadro ha pertenecido siempre a la familia de Navarro-Villoslada, hasta hoy día. En cuanto a la tercera de estas obras, a la que daremos el título de Interior de un templo con figuras de época (Fig. 11), diremos que es una hermosa acuarela sobre papel (más concretamente acuarela con dibujo), técnica ésta en la que Pérez Villaamil fue verdadero maestro y uno de los mejores del siglo XIX español. Pertenece a una colección particular de Barcelona, pero desconozco sus dimensiones. No está firmada, aunque la técnica es indudablemente la de nuestro artista, con los afiligranados 
Fig. 9. Jenaro Pérez Villaamil. Ceremonia religiosa en el interior de la sinagoga del Tránsito de Toledo. $\mathrm{O} / \mathrm{L}$. Paradero desconocido.

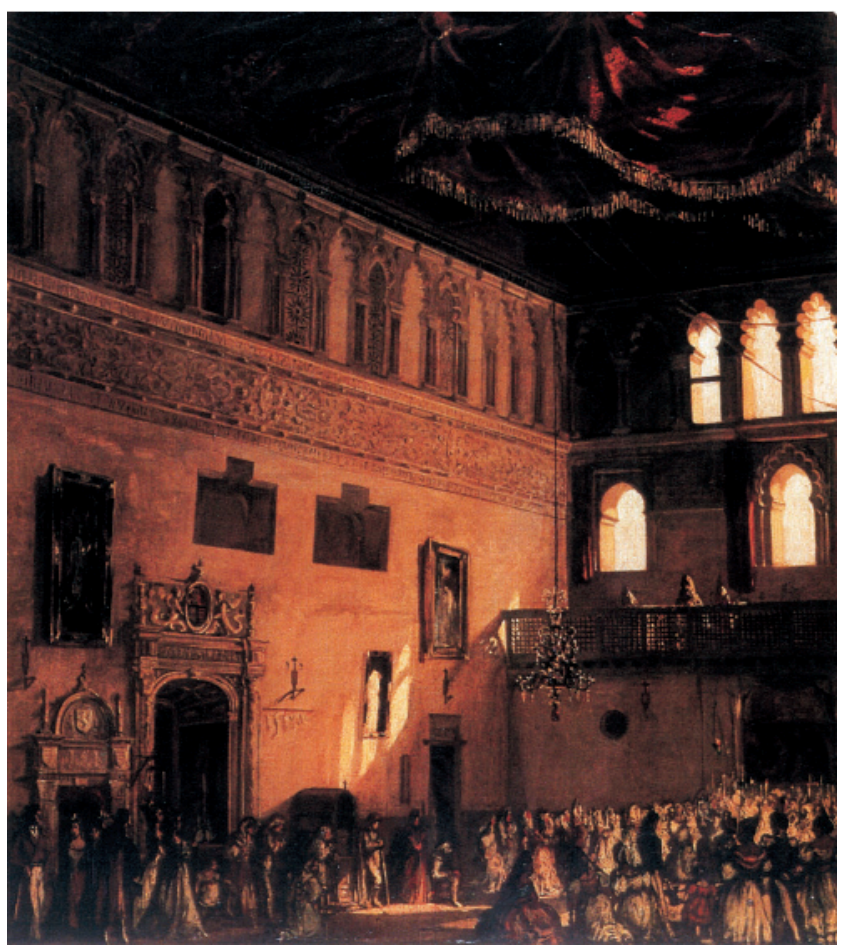

Fig. 10. Jenaro Pérez Villaamil. Interior de iglesia con sepulcros yacentes. O/L. Madrid. Colección particular.

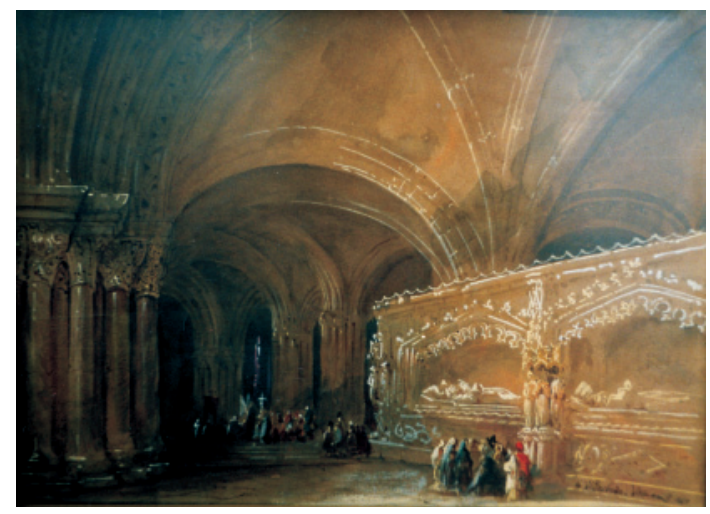

adornos góticos, su característica forma de manchar los personajes y de concebir el ámbito del interior arquitectónico, así como su estructuración lumínica. No podemos precisar de qué iglesia se trate, pensando pueda ser una creación de fantasía o una iglesia extranjera.

De Antonio de Brugada Vila (Madrid, 1804-San Sebastián, 1863) aparecen pocas obras, ya sea en el mercado, ya en colecciones particulares. Quizá esto sea debido al olvido a que lo ha relegado el paso del tiempo, y quizá también, por el hecho de que, habiendo residido gran parte de su vida en Burdeos (Francia), muchas obras suyas se encuentren en colecciones particulares francesas, no alcanzando allí la valoración que le correspondería por haber llegado a ser, con el tiempo, un pintor extranjero desconocido. De aquí el interés que adquiere la aparición de nuevas obras suyas, pues casi todas las que le conocemos en España se encuentran en centros oficiales, 


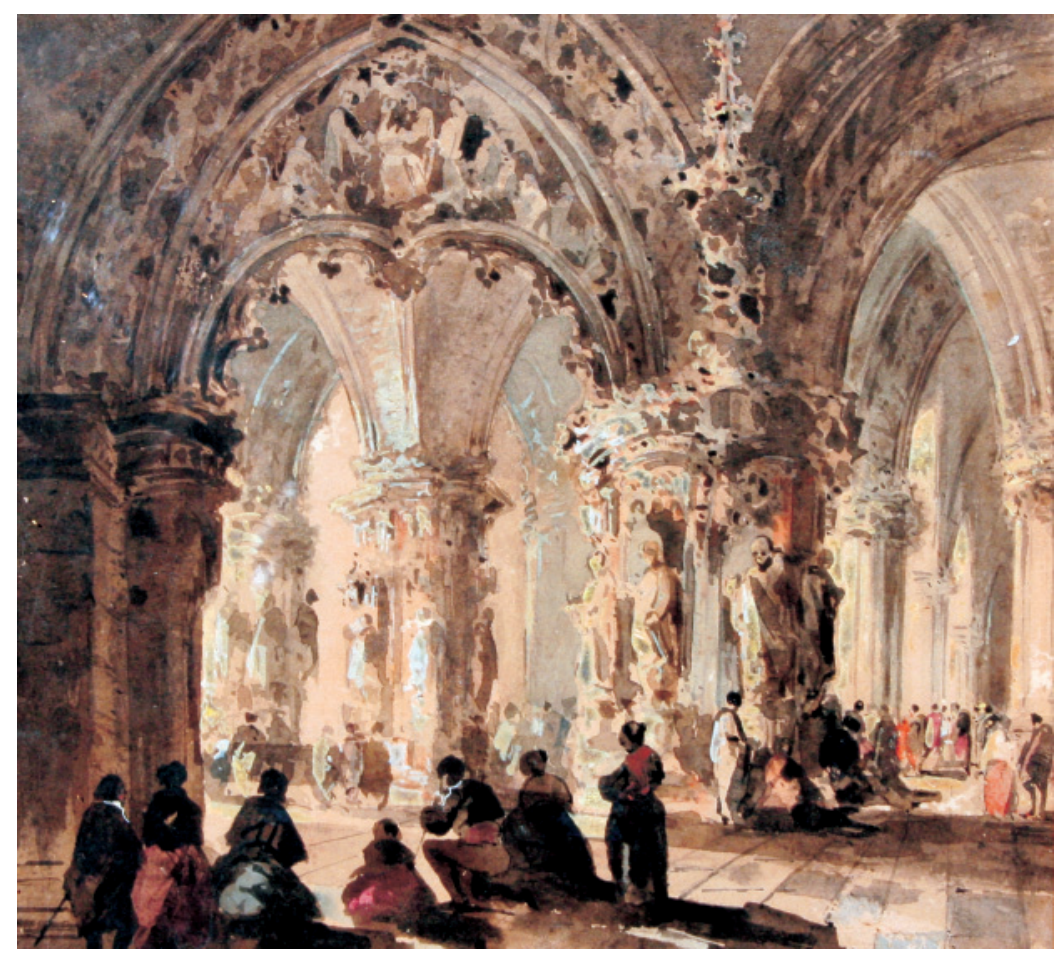

Fig. 11. Jenaro Pérez Villaamil. Interior de un templo con figuras de época. Aguada con dibujo sobre papel. Barcelona. Colección particular.

como el Museo Naval de Madrid, el Museo del Prado, el Patrimonio Nacional, el Museo de San Telmo de San Sebastián y, sobre todo, en la Fundación Santamarca de Madrid, que conserva gran cantidad de cuadros suyos, por haber sido protegido el pintor por el conde de Santamarca ${ }^{24}$.

El primer cuadro que traemos de Antonio de Brugada pertenece a una colección privada madrileña, y es un óleo sobre lienzo, de $90 \times 129 \mathrm{~cm}$., firmado y fechado "A. de Brugada 1844", y que titulamos Vista de la ciudad francesa de Pau (Fig. 12), por interpretar nosotros que de dicha población se trata. Aunque lo más abundante de su producción sean las marinas, Brugada practicó también lo que entendemos por paisaje en su acepción más tradicional, pero estando, en mayor o menor medida, de alguna forma presente el elemento líquido, bien en las lejanías (Paisaje con escena señorial del siglo XVII, Fundación Santamarca, Madrid) ${ }^{25}$, bien organizando el paisaje en torno a alguna charca o río, como sería el caso de Paisaje con cacería junto a un río ${ }^{26}$ (Fundación Santamarca, Madrid) o el del cuadro que aquí tratamos, donde el paisaje se halla totalmente condicionado por la presencia del río, ordenado en torno a su disposición central. El punto de vista del pintor (y por tanto el nuestro) está situado en la misma orilla, que llega a los primeros términos del cuadro. No es una marina, pero se le aproxima por el protagonismo que adquiere en presencia y volumen el elemento líquido, que se nos coloca antes que nada delante la vista, conduciéndonos, por encima de su corriente y sus ondas, hacia la vista de la ciudad que se desarrolla al fondo. Así, tras el puente del Gave se nos eleva en la otra orilla, entre vegetación y variados edificios, la mole del castillo de los vizcondes de Béarn, que reconstruyera en su día el

${ }^{24}$ Arias Anglés, E., Antonio de Brugada. Pintor romántico y liberal. Ayuntamiento de Madrid/Ed. Avapiés, Madrid, 1989.

${ }^{25}$ Ibidem, p. 109 (Fig. 42).

${ }^{26}$ Ibidem, p. 107 (Fig. 41). 


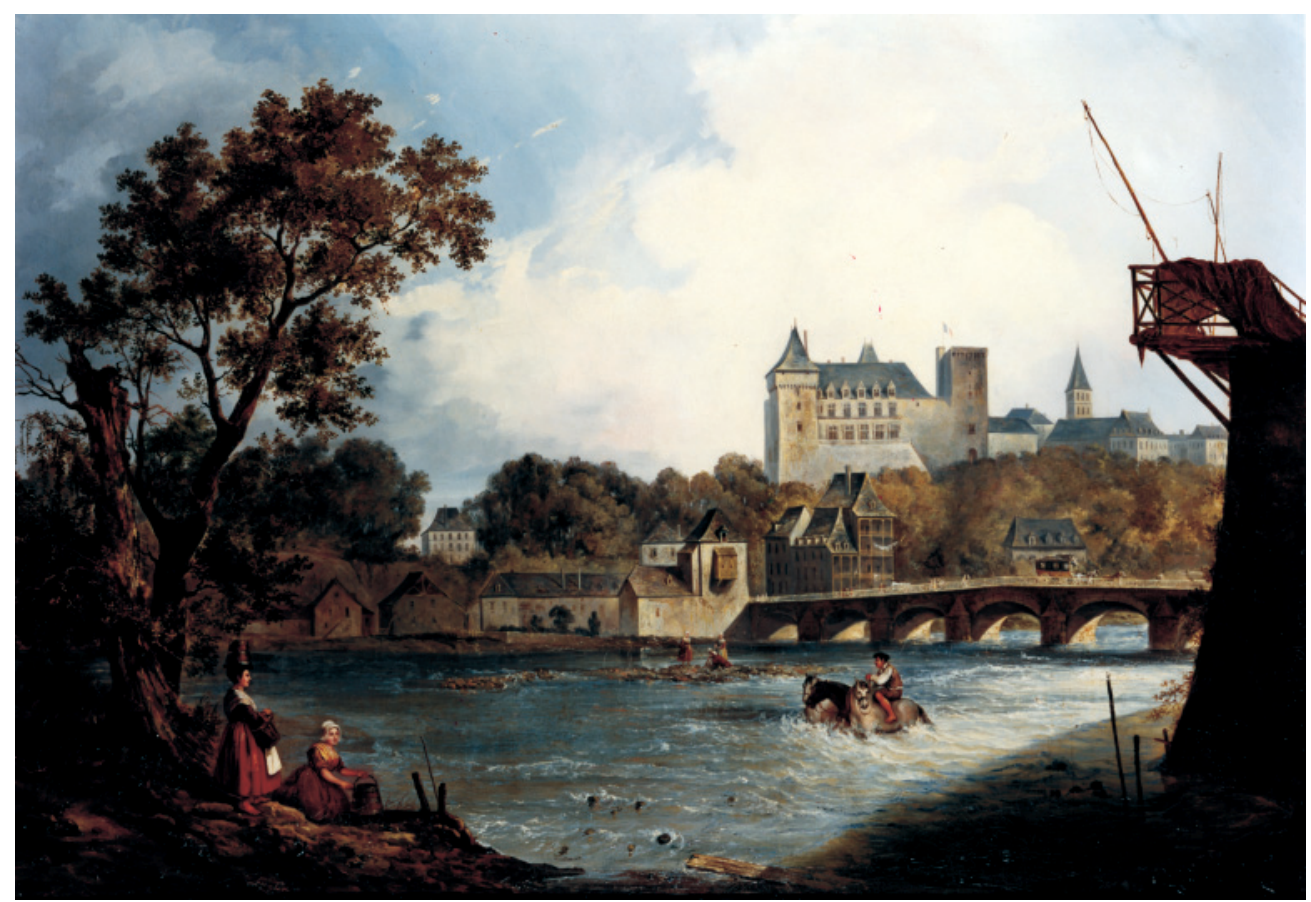

Fig. 12. Antonio de Brugada Vila. Vista de la ciudad francesa de Pau. O/L. Madrid. Colección particular.

célebre Gastón Phoebus y en el que nacería posteriormente el rey Enrique IV de Francia. Como en casi todos los cuadros de Brugada, no falta la presencia humana, en este caso proporcionando sabor local al cuadro, patente en esas lavanderas que se ven al fondo sobre un islote del río, en los personajes y la diligencia que cruzan el puente, en el hombre que a lomos de uno de sus tres caballos trata de cruzar la corriente y en las dos figuras femeninas que, en el lateral izquierdo y bajo unos árboles, acuden a llenar sus recipientes al río. El paisaje está dotado, como en general los de Brugada, de movimiento y estudiada composición, buen dibujo, acordado colorido y abundante empaste, respondiendo a la fama que como pintor de marinas y paisajes gozó en su tiempo.

Además de este cuadro, podemos aportar otros dos paisajes marítimos de Brugada aparecidos recientemente en una subasta de Sotheby's en Londres ${ }^{27}$, provenientes, significativamente, según lo que antes expusimos, de una colección privada francesa. Ambas obras son muy características del pintor, y forman, sin duda, pareja, tanto por la igualdad de dimensiones como por la complementariedad de sus temáticas. De ahí que respetemos los títulos que les proporcionaron en el catálogo de dicha subasta, pues no pueden ser más significativos y, a la vez, descriptivos. Ya que, al ser paisajes con asuntos de fantasía, el protagonismo de los mismos, su más clara característica, viene dada por los elementos luminosos y atmosféricos que les proporcionan tanto el crepúsculo matutino a uno, como el vespertino al otro.

27 Spanish Painting 1850-1930 (1850-1930 Pintura Española). Sotheby's, London, 15 november 2006, pp. 80 (Figs. 207 i y 207 ii) y 81 (Lot 207). 
Veamos por tanto, primeramente, al que se titula Amanecer (Fig. 13); que es un óleo sobre lienzo, de 66,4 ×90 cm., firmado "Ant. de Brugada" 28 . Representa, como decimos, el amanecer en una playa, sin duda valenciana, tanto por el atuendo de los pescadores que están junto a las barcas en el lateral izquierdo del cuadro, como, sobre todo, por las vestimentas típicamente valencianas de las mujeres que aparecen en el lateral derecho a primer plano; a ello se une, para subrayar el ambiente levantino, unas ruinas moriscas, rodeadas de palmeras, sobre un promontorio en el lateral derecho de cuadro. Pero el gran protagonista de la obra es la atmósfera brillante y amarillenta que, como un estallido de luz, envuelve en una bruma dorada los celajes, afectando a todo el ámbito de la composición. Es este un asunto tratado en otras ocasiones por Brugada y muy característico de él, ya que tanto el tema playero, como el tratamiento de la luz, en esa hora determinada, tienen su equivalente en otros cuadros suyos, con los que concuerda éste enormemente, como son Vista del torreón y puerto de Pasajes, del Patrimonio Nacional, o Faro en la playa, de la Fundación Santamarca de Madrid, ambos con asuntos de playas e idénticos efectos lumínicos de amanecer ${ }^{29}$; por no hablar del idéntico efecto atmosférico del crepúsculo matutino que nos muestra su cuadro de historia Alba de América del Museo Naval de Madrid ${ }^{30}$.

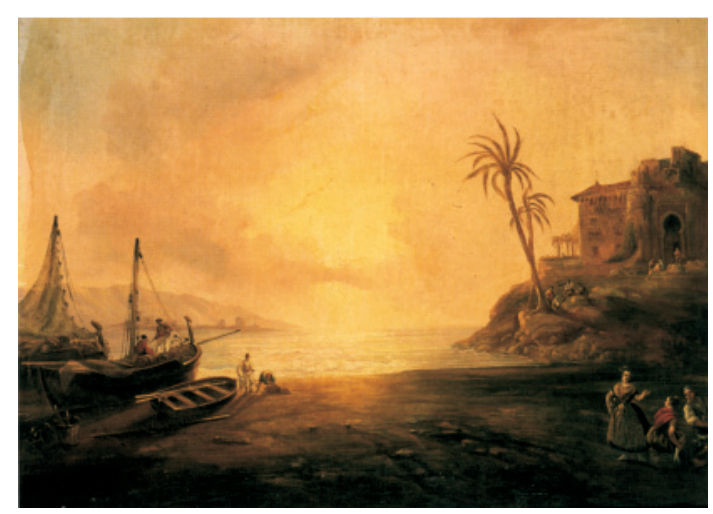

Fig. 13. Antonio de Brugada Vila. Amanecer. O/L. Londres. En el comercio.

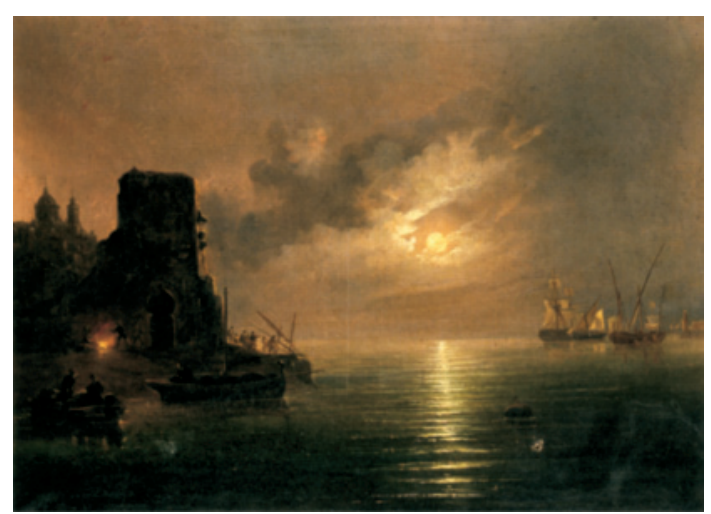

Fig. 14. Antonio de Brugada Vila. Atardecer. O/L. Londres. En el comercio.

El otro cuadro, pareja de éste, subastado en Sotheby's, lleva el complementario título de Atardecer (Fig. 14), y es también un óleo sobre lienzo de $66,4 \times 90 \mathrm{~cm}$., firmado igualmente "Ant. de Brugada" ${ }^{1}$. Al tratarse ya de un asunto iluminado por la incipiente luz de la luna, no podemos determinar por los personajes su ubicación; aunque tanto el tipo de barcos de vela latina que aparecen, idénticos a los del cuadro anterior, así como el torreón con puerta morisca

28 Ibidem.

29 Arias Anglés, E., Antonio de Brugada. Pintor romántico y liberal. Ayuntamiento de Madrid/Ed. Avapiés, Madrid, 1989, pp. 50 (Fig. 20) y 79 (Fig. 28)

30 Ibidem, p. 30 (Fig. 9).

${ }^{31}$ Spanish Painting 1850-1930 (1850-1930 Pintura Española). Sotheby's, London, 15 november 2006, pp. 80 (Figs. 207 i y 207 ii) y 81 (Lot 207). 


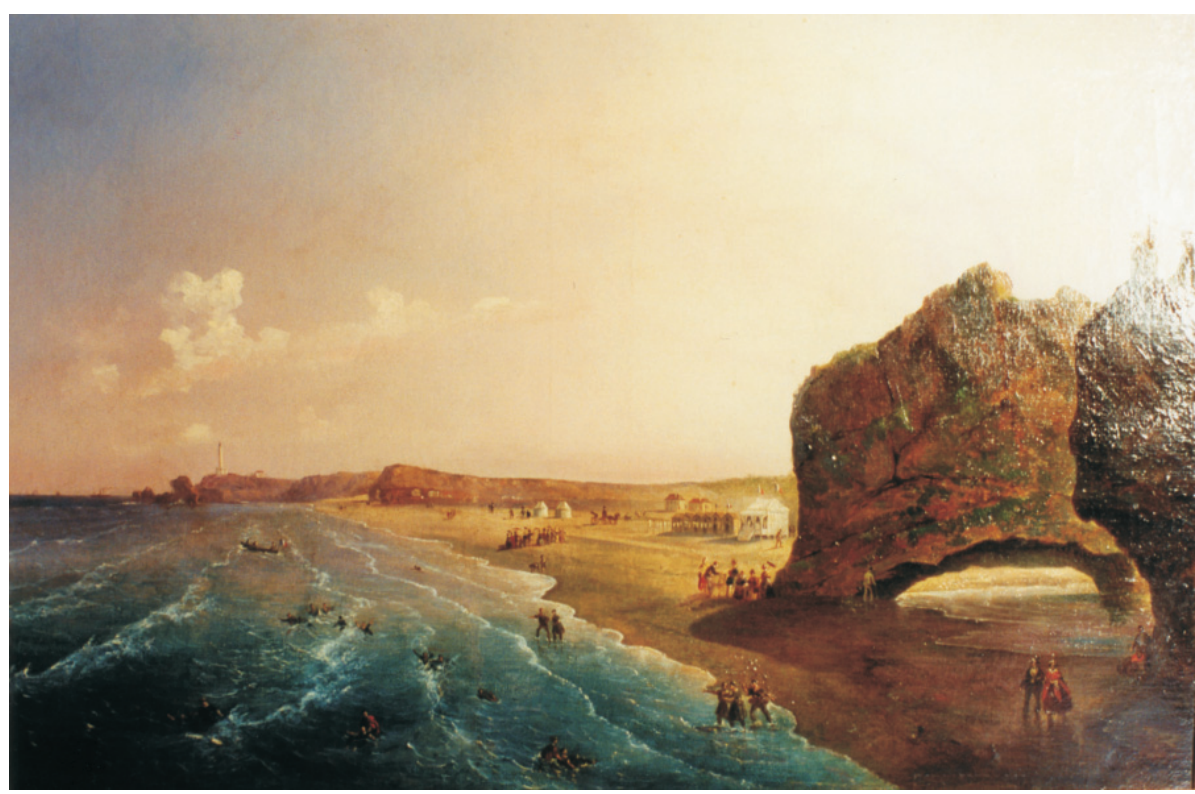

Fig. 15. Antonio de Brugada Vila. La playa de Biarritz. O/L. San Sebastián. Colección particular.

de la izquierda de la composición, tan igual al del otro lienzo, y el tipo de cúpula de la iglesia que se recorta en la penumbra detrás del mismo, parecen indicarnos que también se trata de una vista de un puerto o ensenada de Levante, lo que avala aún más el carácter de pareja de ambos cuadros. Este tipo de cuadro con luz de incipiente luna y algún foco luminoso de hoguera en las zonas más obscuras, es también muy característico de Brugada; teniendo igualmente sus equivalentes en cuadros como Velero saliendo de puerto en la noche y Ensenada a la luz de la luna, ambos de la Fundación Santamarca de Madrid o Marina nocturna, del Patrimonio Nacional ${ }^{32}$.

Y, por último, no queremos dejar pasar por alto un cuadro muy curioso e interesante de Brugada, procedente de una colección particular de San Sebastián, representando La playa de Biarritz (Figs. 15 y 16), que es un óleo sobre lienzo, de 55,5 $\times 85,5 \mathrm{~cm}$., firmado en la parte inferior con tenue trazo "A. de Brugada". Y decimos que es interesante, porque, además de mostrarnos el paisaje playero, tal como era en su momento, tiene el interés añadido de presentarnos la primeriza utilización de dicha playa por los, quizá, primeros veraneantes, así como las iniciales instalaciones construidas para su servicio. Veraneo que, aunque minoritario, no dejaba de estar perfectamente organizado, según se nos muestra en el cuadro, con sus hotelitos, casetas para bañistas, servicio de carruajes e, incluso, un bote con socorristas. Cuadro lleno de anécdotas playeras, protagonizadas por diversos grupos de bañistas, que nos ilustran a la perfección sobre cómo era un veraneo de aquel momento.

Del paisaje realista, traemos un cuadro de Carlos de Haes (Bruselas, 1826-Madrid, 1898), aparecido en el comercio de Alicante, que titularemos, por su temática, Paisaje de alta montaña

32 Arias Anglés, E., Antonio de Brugada. Pintor romántico y liberal. Ayuntamiento de Madrid/Ed. Avapiés, Madrid, 1989, pp. 70 (Fig. 27), 84 (Fig. 30) y 90 (Fig. 34). 


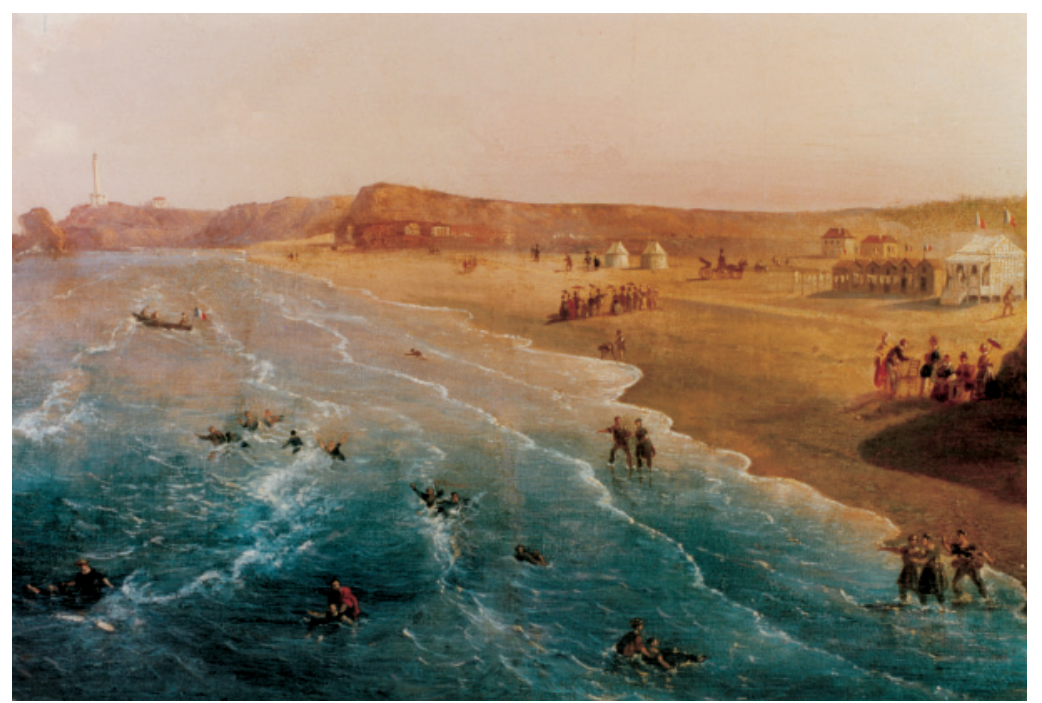

Fig. 16. Antonio de Brugada Vila. La playa de Biarritz. (Detalle). O/L. San Sebastián. Colección particular.

con camino y arroyo (Fig. 17), que es un óleo sobre lienzo de $97 \times 146 \mathrm{~cm}$., firmado, en el ángulo inferior izquierdo " $C$. de Haes". Nos representa un paisaje montañoso dividido en dos por un pequeño torrente o arroyo que, viniendo del fondo, desemboca en el primer plano al centro del cuadro, formando así un eje con el alto picacho montañoso que domina el horizonte de la composición; tipo de estructura ésta que aplicó a algunos de los cuadros de alta montaña que realizó. Se trata de una obra de estudio, de buen tamaño y minuciosamente terminada, lo que la diferencia bastante, estilística y técnicamente, de los numerosos apuntes abocetados que realizaba del natural y que le servían luego para componer cuadros perfectamente acabados en su taller, siguiendo la práctica de los pintores del naturalismo; bocetos éstos que se caracterizan por una técnica más suelta y espontánea. Estilísticamente el cuadro sería clasificable en la segunda de las tres etapas en que Cid Priego ${ }^{33}$ dividió la producción pictórica de Carlos de Haes. Esta etapa la acota dicho autor entre 1870 y 1880 , período en el que Haes abandona la fuerte construcción dibujística, los tonos terrosos y los asfaltos oscuros que dominaron en su primera período, para abrirse en esta segunda etapa a un mayor aclaramiento de su paleta y a una factura más suelta, como es el caso de la obra que tratamos que, a pesar de su tendencia hacia una tonalidad de cierta monocromía, ofrece una gran riqueza de matices cromáticos y suaves contrastes lumínicos, jugando con las variaciones del color en cada zona del lienzo, determinadas esas variaciones por la diversa intensidad de la luz. Coincide, además, en este caso, la datación de dicho período estilístico con el despertar del interés de Haes por los paisajes de alta montaña, cuando entró en contacto con este tipo de paisajes en sus viajes artísticos a Santander, Vasconia y Navarra, descubriendo así los paisajes del norte de España, especialmente los de los Picos de Europa y los Pirineos, lo que sucedió entre los años de 1872 y 1875 , por lo que en torno a estas fechas debió de realizar el lienzo.

El cuadro guarda algunas similitudes con otras obras y bocetos del pintor, reseñados en el Catálogo de la producción del artista conservada en el Museo del Prado, como cierta coincidencia

33 Cid Priego, C., Aportaciones para una monografía del pintor Carlos de Haes, Instituto de Estudios Ilerdenses, CSIC, Lérida, 1956, pp. 18, 21, 22. 


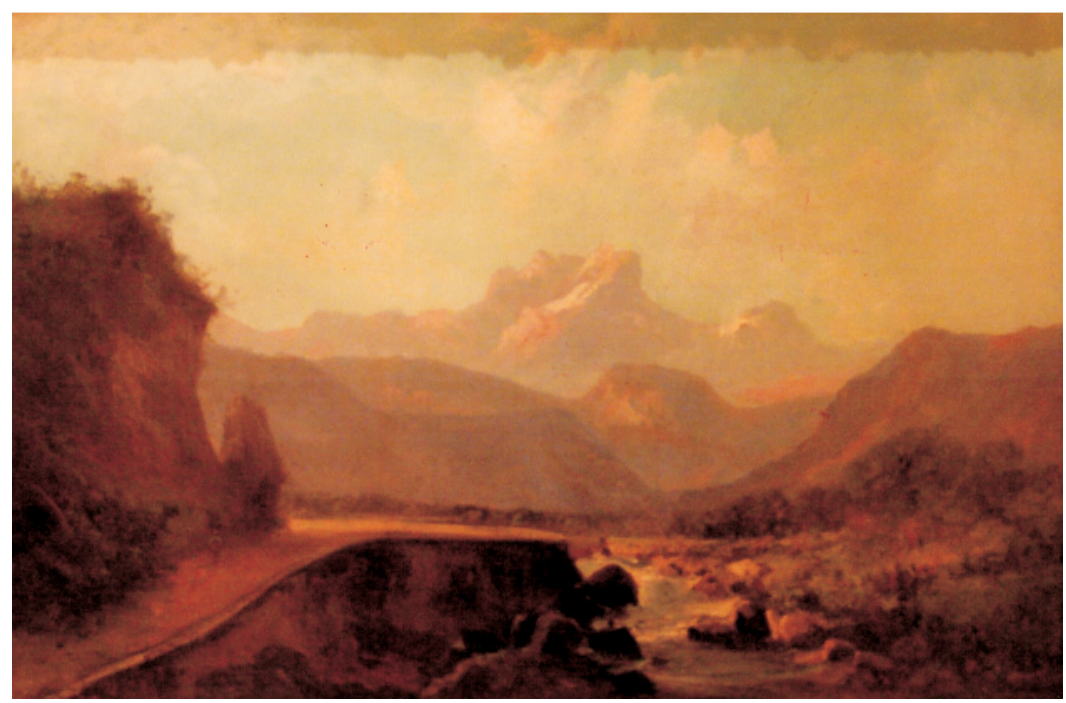

Fig. 17. Carlos de Haes. Paisaje de alta montaña con camino y arroyo. O/L. Alicante. En el comercio.

estructural en su composición con el dibujo, de hacia 1874, titulado Peña de Rodrigario (Pajares) $\left(N^{\circ}{ }^{\circ} \text { D-5218 del citado Catálogo }\right)^{34}$ (Fig. 18), incluido el similar camino de montaña que vemos al lado izquierdo de ambas obras; igualmente llama la atención la gran semejanza del promontorio del lateral izquierdo del cuadro con el acantilado del también lateral izquierdo del boceto titulado

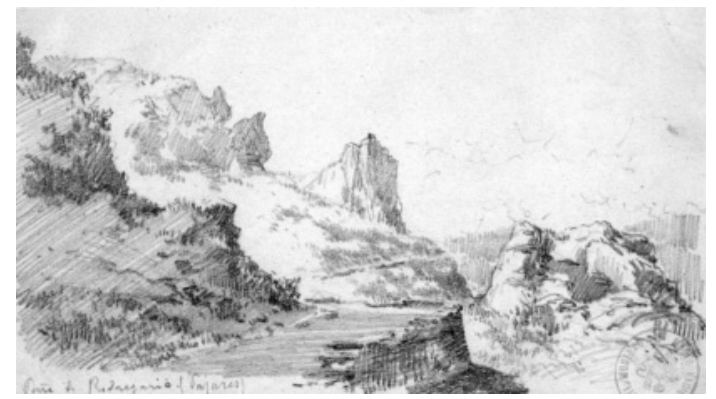

Fig. 18. Carlos de Haes. Peña de Rodrigario (Pajares). Dibujo a lápiz sobre papel. Madrid.

Museo del Prado.

Fig. 19. Carlos de Haes. Costa de Douarnenez (Bretaña). O/L. Madrid. Museo del Prado (Depositado en Lérida. Museo Jaime Morera).

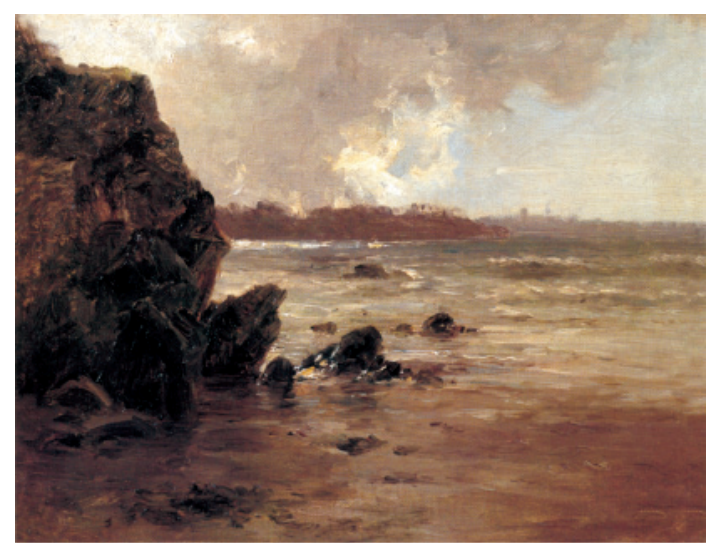

34 Gutiérrez Márquez, A., Carlos de Haes en el Museo del Prado (1826-1898). Catálogo razonado. Museo Nacional del Prado, 2002, pp. 110 y 111 (D-5218). 
Costa de Douarnenez (Bretaña) (N. $\left.{ }^{\circ} 7488\right)^{35}$ (Fig. 19), fechable hacia 1877-1884; y también es semejante, por su tendencia hacia una monocromía de tonos ocres o terrosos, dominantes en el lienzo, a otros cuadros y bocetos de dicho Museo, realizados dentro del amplio abanico cronológico que va desde 1860 (Un país. Recuerdos de Andalucía, costa del Mediterráneo, junto a Torremolinos, N. ${ }^{\circ}$ 4836), 1862 (Despeñaperros, N. ${ }^{\circ}$ 5671), 1872 (Noria abandonada. Alrededores de Madrid, N. ${ }^{\circ}$ 7482) (Unos desmontes. Cercanías de Madrid, N. ${ }^{\circ} 7514$ ), a 1876 (Torremolinos. Málaga, N. $\left.{ }^{\circ} 6864\right)^{36}$.

De Antonio Muñoz Degraín (Valencia, 1840-Valencia, 1924), sucesor de Haes al frente de la cátedra de Paisaje de la Escuela de la Academia de San Fernando, traemos cuatro cuadros, pertenecientes a una colección privada de la comunidad valenciana: tres paisajes y un drama humano, todos ellos impregnados del simbolismo que caracteriza a gran parte de la obra de tan polifacético $\mathrm{y}$ vitalista pintor. Trataremos juntamente a los dos primeros, ya que vienen a ser pareja, por sus idénticas dimensiones y temáticas complementarias. Uno de ellos lo titularemos, de acuerdo con su asunto, Nocturno en la laguna de Venecia (Fig. 20), y al otro, Vista de la laguna de Venecia (Fig. 21), y nos representa una vista diurna de dicha ciudad. Ambos son óleos sobre lienzo, de $62 \times 92$ cm., estando firmados los dos en el ángulo inferior izquierdo: "A. M. Degraín".

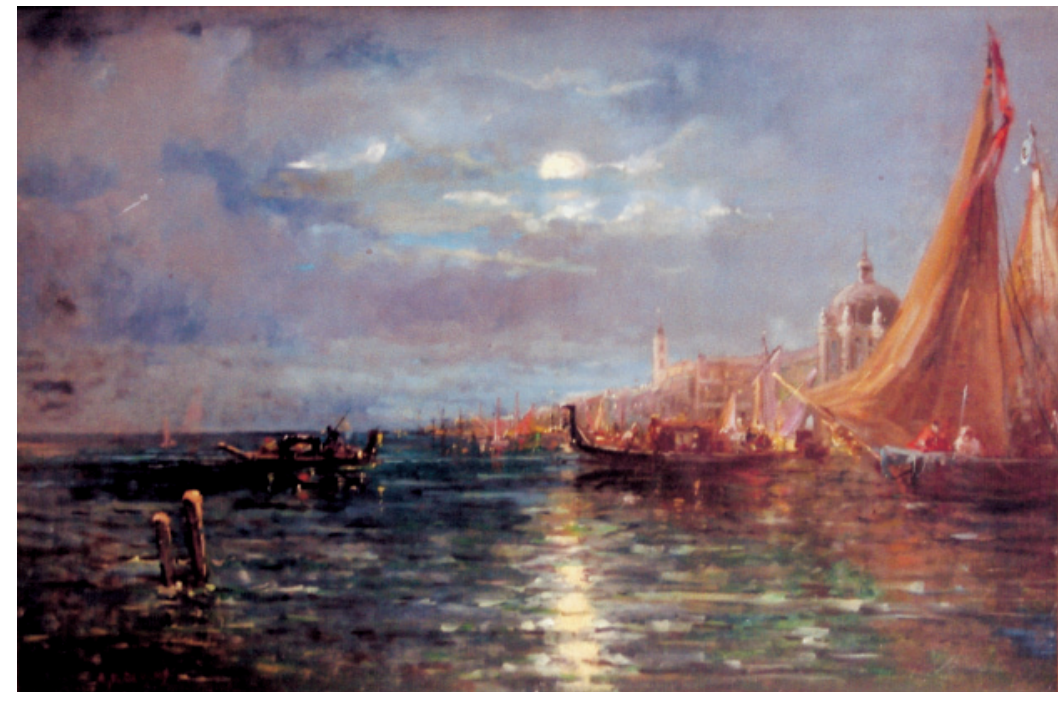

Fig. 20. Antonio Muñoz Degraín. Nocturno en la laguna de Venecia. $\mathrm{O} / \mathrm{L}$. Alicante. Colección particular.

Muñoz Degraín visitó en varias ocasiones Venecia, mostrando la fascinación que esta ciudad ejerció sobre él, al igual que sobre otros muchos artistas del momento, mediante la realización de paisajes venecianos, pero con un tratamiento bien diferente al que dieron a estos asuntos otros pintores españoles de esa época, como Martín Rico o Reyna Manescau, por ejemplo, a quienes podemos considerar aún dentro de la estela de un naturalismo no exento de recuerdos de la pintura de Fortuny. En efecto, la pintura de Muñoz Degraín está cargada de un ingrediente que faltaba en todos esos pintores: el exotismo, que solía traducirse no sólo en los temas que trataba, sino también en la técnica que empleaba para ejecutarlos, empastada y con brillantez en la vibrante libertad de pincelada, así como por su deliciosa y audaz fantasía cromática, lo que da a muchas

\footnotetext{
35 Ibidem, pp. 244 y 245 (7488).

36 Ibidem, pp. 146-147, 198-199, 200-201.
} 
Fig. 21. Antonio Muñoz Degraín. Vista de la laguna de Venecia. $\mathrm{O} / \mathrm{L}$. Alicante.

Colección particular.

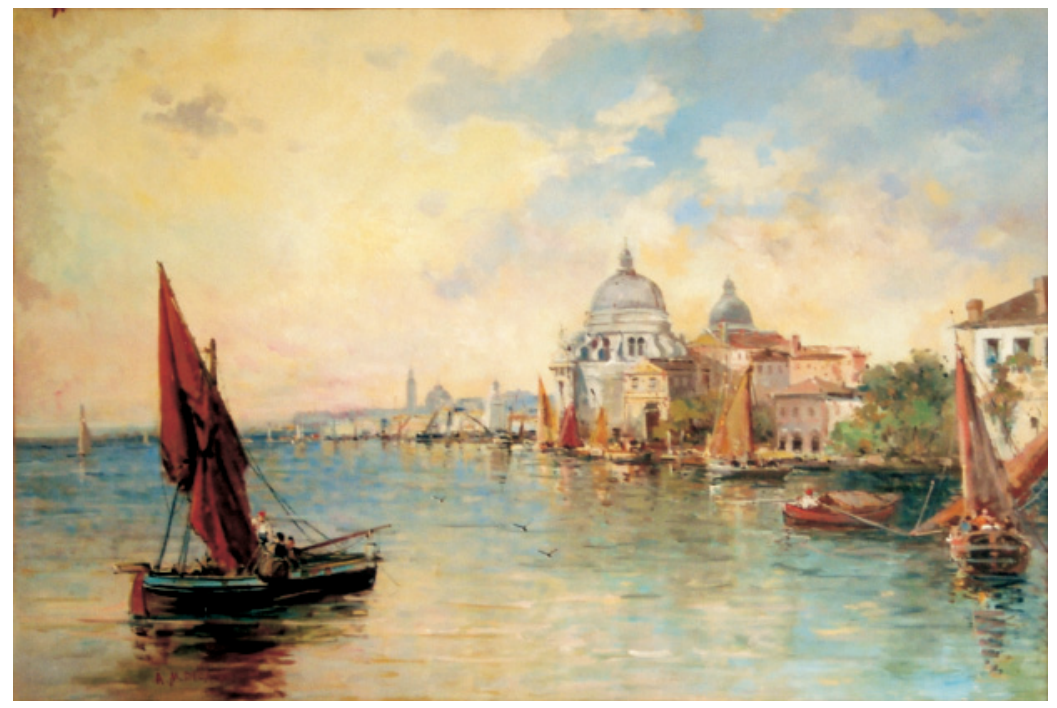

de sus obras un especial encanto poético, convirtiendo a sus paisajes en vehículos de emociones que trascienden las meras sensaciones visuales del paisajismo realista tradicional. Su arte, aunque enmarcado en la época del realismo, hunde sus raíces en el romanticismo para enlazar con el simbolismo. Características éstas que son perfectamente apreciables en estos dos cuadros que estudiamos, donde, en el primero de ellos, la misma temática, mostrándonos una visión nocturna de la laguna de Venecia, cargada de fantasía y encanto en su ambientación, nos lo despegan de las tradicionales vistas de Venecia llenas de la brillante luz del día reflejada en pequeños toques de pasta, para acercarnos a un tratamiento del asunto con claros tintes románticos y un atrevimiento colorista de magistral libertad de pincelada, que le proporciona aspectos casi mágicos y que lo aproxima al simbolismo ${ }^{37}$. Pocos fueron los pintores que trataron el nocturno veneciano, pero a Muñoz Degraín se le conocen varios, como a continuación veremos.

Por lo que respecta al otro cuadro, a pesar de que representa una vista diurna de la laguna de Venecia, al igual que sucede en el cuadro anterior, se nos muestra una vista veneciana alejada de los tópicos y técnicas de los otros muchos pintores españoles que por aquellas fechas visitaron la ciudad de Venecia. Coincide Muñoz Degraín aquí con ellos en el asunto, pero, al igual que en el otro cuadro, se distancia también por su fuerte y marcada personalidad, por su penetrante y singular sentido de la composición, la luz y el color. La vista que nos presenta Muñoz Degraín está cargada de fantasía poética y encanto en su atmósfera, colorido y ambientación, acercándonos a un tratamiento del asunto con claros tintes románticos y un atrevimiento colorista que le proporciona aspectos casi exóticos.

Pensamos que estos cuadros los realizase durante su primera estancia en Venecia, entre 1882 y 1883, estando de pensionado en la Academia Española de Bellas Artes de Roma, por comparación con otros nocturnos venecianos suyos posteriores, fechados en 1886 (La laguna de Venecia. Museo Provincial de Santa Cruz de Tenerife),1887 (Serenata en el Gran Canal. Málaga. Colección particular), o Nocturno veneciano (Valencia. Colección particular), de un más

${ }^{37}$ Para una mayor información al respecto, véanse los documentados e interesantes estudios de JULIÁN GÁLLEGO ("El exotismo en Muñoz Degraín") y JaVIER Pérez Rojas ("Muñoz Degraín entre el realismo y el wagnerianismo de fin de siglo") en Antonio Muñoz Degraín (Valencia 1840-Málaga 1924). Catálogo. Comisario exposición Ramón García Alcaraz. Caja de Madrid, Sala de las Alhajas, Madrid, octubre/diciembre, 1995, pp. 11 a 32. 
intenso sabor neorromántico y aproximación simbolista en la ambientación y colorido ${ }^{38}$. Pero, de todas formas, tanto en este que tratamos, como en los citados, está claramente presente ese aspecto exótico y encanto poético a que hemos aludido que, con la preeminente presencia de la luna llena que asoma entre las nubes, presente en todos ellos, proporciona una iluminación casi mágica a las escenas.

El tercer cuadro que traemos de Muñoz Degraín, y que titularemos Devota ofrenda en la laguna de Venecia (Fig. 22), es otro óleo sobre lienzo, de 48,5 × 70,5 cm., firmado en el margen inferior izquierdo "Muñoz Degraín. Venezia", perteneciente a una colección privada alicantina. Tiene por asunto también una vista nocturna de la laguna veneciana, en la que la brillante luz de la luna, que asoma entre densos nubarrones (efecto tan característico de otros nocturnos de Muñoz Degraín), nos permite apreciar, el ámbito de la laguna con góndolas y barcos de vela; al fondo izquierda, en penumbra, la silueta de la iglesia de la Salute, y al primer término, al centro del cuadro, una joven, en pie sobre un bote que gobierna un barquero, coloca unas flores en un altar que se alza sobre unos pilotes en medio de las aguas, altares presentes en otras obras sobre la laguna de Venecia de Muñoz Degraín, como Nocturno veneciano (colección particular. Valencia) o La laguna de Venecia (Santa Cruz de Tenerife. Museo de Bellas Artes), anteriormente citados ${ }^{39}$. Las penumbras y la pálida brillantez de la luz lunar prestan un aspecto misterioso, cargado de tintes románticos, a la escena.

No menos romántico es el asunto del cuarto cuadro de Muñoz Degraín, de los que analizamos. Se trata de un óleo sobre lienzo, de $60 \times 40 \mathrm{~cm}$., firmado "A. Muñoz Degraín” en el margen inferior derecho, y que podríamos titular de muchas formas, aunque a nosotros nos ha parecido adecuado el de Clamando venganza (Fig. 23). Estamos ante un drama humano, pero un drama de herencia romántica, ya que nos muestra la impotencia del ser humano ante las fuerzas desatadas de la naturaleza, asunto éste que gustó representar en varias ocasiones Muñoz Degraín, como las diversas versiones que realizó con el tema de la inundación, siendo el primero de ellos Episodio de una inundación. Murcia, cuadro que envió desde Roma como pensionado de mérito de la

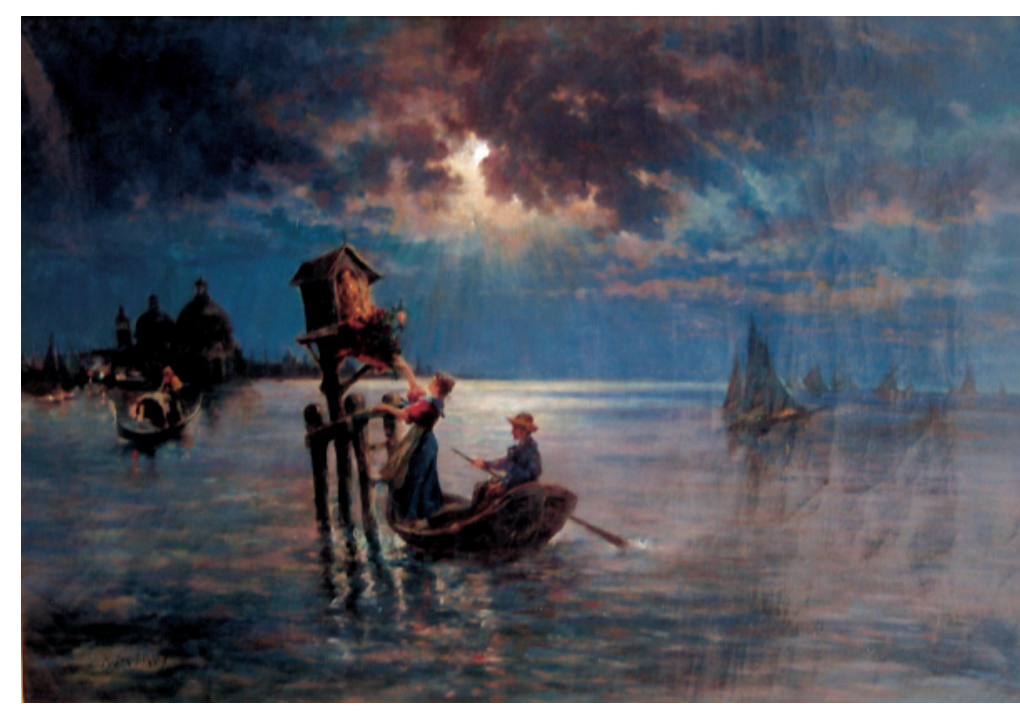

Fig. 22. Antonio Muñoz Degraín. Devota ofrenda en la laguna de Venecia. $\mathrm{O} / \mathrm{L}$. Alicante. Colección particular.

38 García Alcaraz, R. (comisario), "Catálogo", en Antonio Muñoz Degraín (Valencia 1840-Málaga 1924). Catálogo exposición. Caja de Madrid, Sala de las Alhajas, Madrid, octubre/diciembre, 1995, pp. 138 a 141.

39 Ibidem, p. 140. 


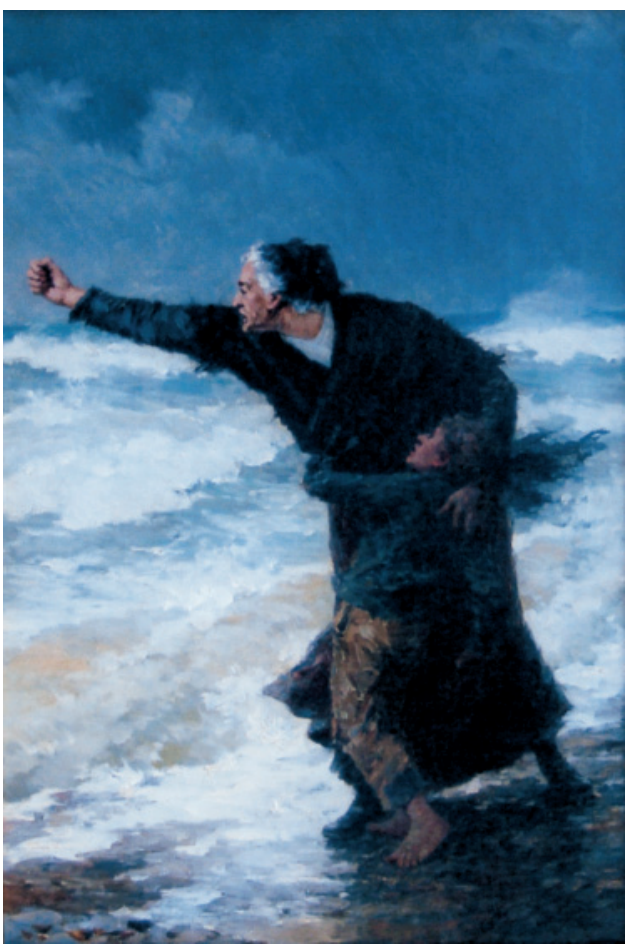

Fig. 23. Antonio Muñoz Degraín. Clamando venganza. $\mathrm{O} / \mathrm{L}$. Alicante. Colección particular.

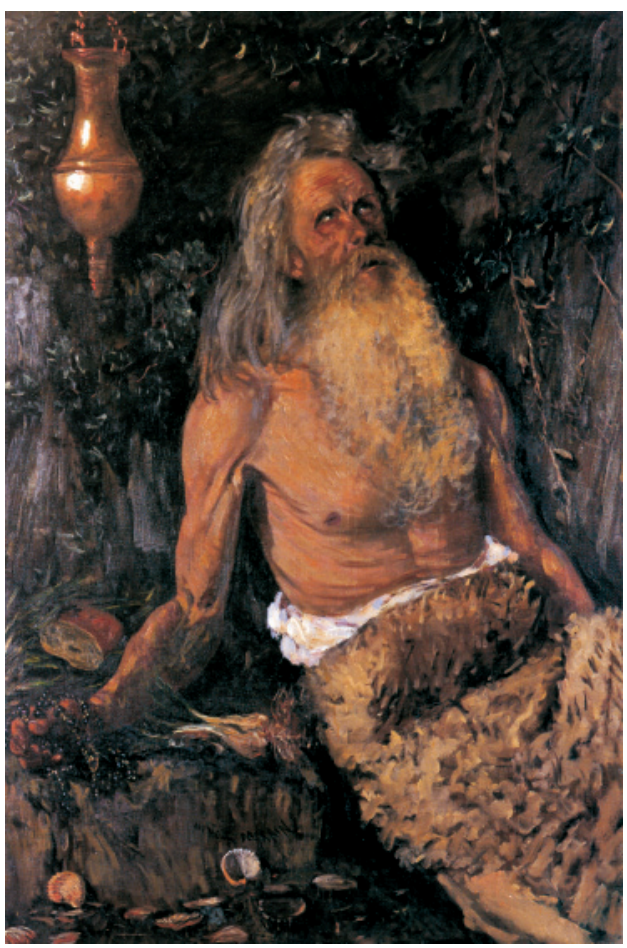

Fig. 24. Antonio Muñoz Degraín. Anacoreta. O/L. Valencia. Museo de San Pío V.

Academia de España en esa ciudad. En este cuadro que traemos se nos muestra a una anciana, a la orilla de un mar embravecido, de cara al viento, y bajo un cielo de galerna, amenazando al oleaje con el brazo extendido, el puño cerrado y un rostro de desesperada iracundia, mientras se agarra desesperadamente a su cintura un niño de unos nueve o diez años. Es fácil la lectura de la imagen: la anciana madre del marinero amenazando al mar, culpable de la muerte de su hijo, que la deja sola con un joven nieto. La técnica del lienzo responde a la utilizada por Muñoz Degraín en otros cuadros suyos; así por ejemplo, la realización de las aguas al primer término, bajo los pies de los personajes, a base de trazos cortos de pincelada, algo alargados, se corresponde con la representación de las aguas del Jordán en el primer término del cuadro San Juan Bautista en el Jordán (Valencia. Museo de San Pío V) ${ }^{40}$, o con las aguas y la forma de realizar los celajes del cuadro Sierra de Guadarrama. Torrente de Los Lirios (Idem) ${ }^{41}$; el rostro de la anciana se asemeja en su factura al de Colón en el cuadro Regreso de Colón enfermo (Madrid. Círculo de Bellas Artes) $)^{42}$ y la deshecha factura del pantalón del niño es muy semejante a la de la piel que viste el personaje del cuadro Anacoreta (Valencia. Museo de san Pío V) ${ }^{43}$ (Fig. 24), a base de cortas y nerviosas pinceladas que dan un aspecto de movida rugosidad a ambas prendas.

40 García Alcaraz, R. (comisario), Antonio Muñoz Degraín (Valencia 1840-Málaga 1924). Catálogo exposición. Caja de Madrid, Sala de las Alhajas, Madrid, octubre/diciembre, 1995, p. 111.

${ }^{41}$ Ibidem, pp. 164-165.

42 Ibidem, pp. 228-229.

43 García Alcaraz, R., El orientalismo en la pintura de Antonio Muñoz Degraín. Catálogo exposición. Generalitat Valenciana, Direcció General de Museus i Belles Arts, Valencia, 1996, pp. 116-117. 
Y, por último, dentro de esta galería catalográfica de paisajes decimonónicos españoles, traemos un típico paisaje rural de Marceliano Santa María (Burgos, 1866-Madrid, 1952), semejante a los muchos que pintó con escenas sencillas de las humildes calles de los pequeños pueblos castellanos. Se trata de un óleo sobre lienzo, de $61 \times 38 \mathrm{~cm}$., y que representa, como decimos, la Vista de una calleja de un pueblecito castellano (Fig. 25), construida en curva sobre una ligera pendiente; curvatura de trazado a que obligó, sin duda, el bloque de granito que aparece en la parte derecha de la callejuela, teniendo éste, en frente, la línea cóncava de las fachadas de las casucas del otro lado del callejón.

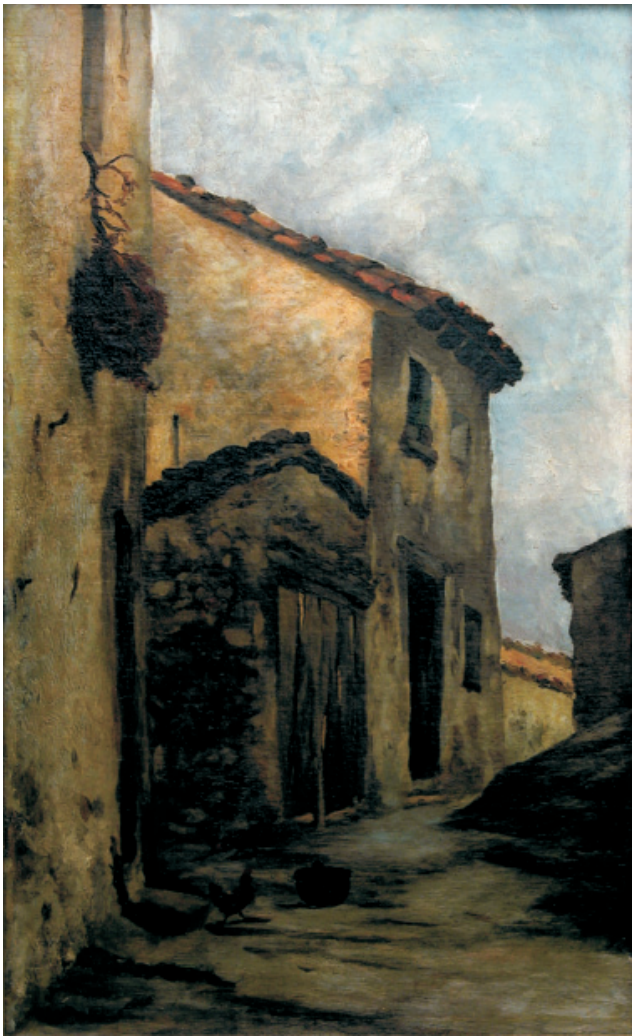

Fig. 25. Marceliano Santa María. Vista de una calleja de un pueblecito castellano. O/L. Madrid. Colección particular.

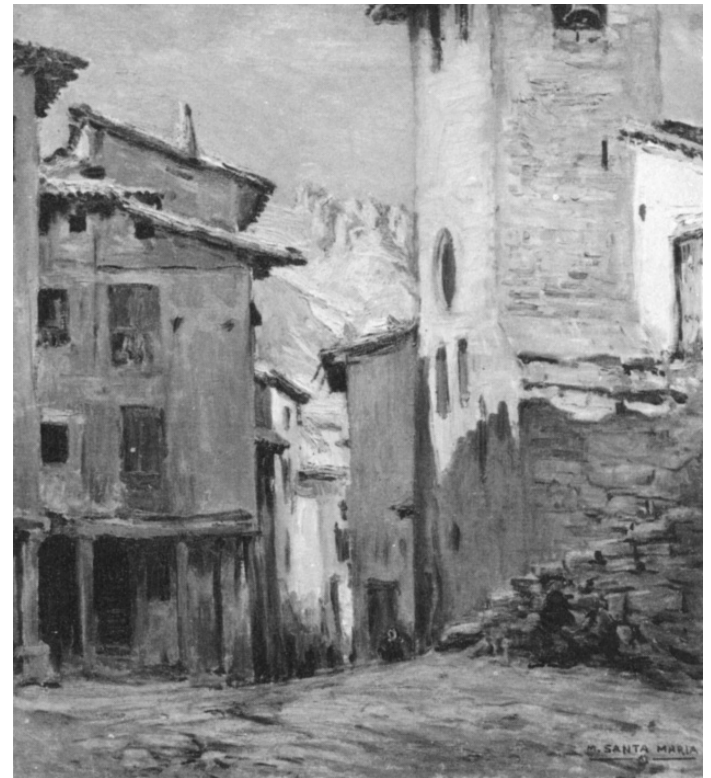

Fig. 26. Marceliano Santa María.

Calle de Marceliano Santa María. O/L. Burgos.

Museo Municipal Marceliano Santa María.

Por su técnica, no se trata de un cuadro de su período impresionista, sino que podríamos considerarlo representativo de su etapa estilística pre-impresionista, naturalista con recuerdos de Corot, a que aludió Camón Aznar ${ }^{44}$. Es más, se podría decir que, a lo largo de la obra paisajista de Santa María, se pueden apreciar momentos alternativos tanto de predominio "corotiano" como de puramente impresionistas ${ }^{45}$. $\mathrm{Y}$, tanto unos como otros -al margen de la técnica- le llevan

${ }^{44}$ Campoy, A. M., "Marceliano Santa María, pintor de Castilla", en Museo Municipal Marceliano Santa María. Burgos. Catálogo general. Excmo. Ayuntamiento de Burgos. Burgos, 1981, p. 15.

45 Ibidem. 
irremediablemente a un descubrimiento de la naturaleza concebido como una vivencia de la realidad, lejos del amaneramiento y del esteticismo ${ }^{46}$; conformando esa "grave versión realista de la naturaleza" 47 , su fluir alegre o melancólico, como una interpretación humilde de un asunto sencillo, de donde brota espontánea la obra de arte. Sencillez lejana de la pedantería, poesía de lo humilde descrito con amor y, valga la redundancia, con humildad, con directa veracidad, captando la impresión del instante.

El tema de una callejuela de pueblo con algunos (pocos) campesinos y gallinas por medio, o simplemente con gallinas, sin alguna presencia humana, fue bastante tratado por Santa María, hallándose abundantes ejemplos de ello en el mismo Museo Municipal Marceliano Santa María de Burgos. Citaremos algunos de los que consideramos más representativos por su semejanza con el que estamos tratando, tanto en la estructura de las casas populares como en la concepción de las aves presentes. Así, el titulado San Medel (n. ${ }^{\circ}$ 9/493 del catálogo) ${ }^{48}$, con algunas casas, en la parte derecha de la calle, muy semejantes a las de este cuadro, como lo son también las gallinas allí representadas. Similitudes muy cercanas, en arquitecturas populares y aves, hallamos también en cuadros como Bochorno (n. ${ }^{\circ}$ 22/487 catálogo), Aldea solitaria (n. ${ }^{\circ} 44 / 100$ catálogo), Tarde apacible (n. ${ }^{\circ} 59 / 566$ catálogo), La solana $\left(n .^{\circ} 65 / 540\right.$ catálogo) ${ }^{49} \mathrm{y}$, sobre todo, en los denominados Casucas (n. ${ }^{\circ}$ 68/278 catálogo) ${ }^{50}$, donde las casas y aves guardan una gran semejanza técnica, estética y estilística con las del cuadro que estudiamos, y Calle de Marceliano Santa María (n. ${ }^{\circ}$ 80/9 catálogo) ${ }^{51}$ (Fig. 26), en el que, si bien no aparecen las aves de corral sueltas del anterior cuadro, la semejanza de las casucas con las de este cuadro, así como su idéntica técnica de realización, nos reafirman las comparaciones efectuadas de esta obra con los cuadros anteriores y nos corroboran la paternidad de la misma por parte de Marceliano Santa María.

Fecha de recepción: 26-VI-2007

Fecha de aceptación: 5-IX-2007

46 Ibidem, pp. 14 y 15

47 Camón Aznar, J., "Paisajes Burgaleses", en Museo Municipal Marceliano Santa María. Burgos. Catálogo general. Excmo. Ayuntamiento de Burgos. Burgos, 1981, p. 24.

48 Museo Municipal Marceliano Santa María. Burgos. Catálogo general. Excmo. Ayuntamiento de Burgos. Burgos, 1981, p. 32 (N. $\left.{ }^{\circ} 9 / 493\right)$

${ }^{49}$ Ibidem, pp. 37 (N.o $\left.22 / 487\right), 48$ (N. $\left.{ }^{\circ} 44 / 100\right), 54$ (N. $\left.{ }^{\circ} 59 / 566\right)$ y 57 (N. $\left.{ }^{\circ} 65 / 540\right)$.

${ }^{50}$ Ibidem, p. 59 (N. $\left.{ }^{\circ} 68 / 287\right)$.

${ }^{51}$ Ibidem, p. 65 (N. $\left.{ }^{\circ} 80 / 9\right)$. 